\title{
TCC-III Engine Benchmark for Large-Eddy Simulation of IC Engine Flows
}

\author{
P. Schiffmann ${ }^{1 *}$, S. Gupta ${ }^{1,2}$, D. Reuss' ${ }^{1}$, V. Sick' ${ }^{1}$ X. Yang ${ }^{2}$ and T.-W. Kuo ${ }^{2}$ \\ ${ }^{1}$ University of Michigan, 1231 Beal Ave, 2045 Auto Lab, Ann Arbor, Ml 48109 - USA \\ 2 Propulsion Systems Research Lab, GM Global R\&D - Warren, MI - USA \\ e-mail: pschiffm@umich.edu - 108.saurabh@gmail.com -dreuss@umich.edu -vsick@umich.edu \\ xiaofeng.yang@gm.com - tang-wei.kuo@gm.com \\ * Corresponding author
}

\begin{abstract}
A collaborative effort is described to benchmark the TCC-III engine, and to illustrate the application of this data for the evaluation of sub-grid scale models and valve simulation details on the fidelity of Large-Eddy Simulations (LES). The TCC-III is a spark ignition 4-stroke 2-valve engine with a flat head and piston and is equipped with a full quartz liner for maximum optical access that allows high-speed flow measurements with Particle Image Velocimetry (PIV); the TCC-III has new valve seats and a modified intake-system compared to previous configurations. This work is an extension of a previous study at an engine speed of 800 RPM and an intake manifold pressure (MAP) of $95 \mathrm{kPa}$, where a one-equation eddy viscosity LES model yielded accurate qualitative and quantitative predictions of ensemble averaged mean and RMS velocities during the intake and compression stroke. Here, experimental data were acquired with parametric variation of engine speed and intake manifold absolute pressure to assess the capability of LES models over a range of operating conditions of practical relevance. This paper focuses on the repeatability and accuracy of the measured PIV data, acquired at $1300 \mathrm{RPM}$, at two different MAP (95 kPa and $40 \mathrm{kPa})$, and imaged at multiple data planes and crank angles. Two examples are provided, illustrating the application of this data to LES model development. In one example, the experimental data are used to distinguish between the efficacies of a one-equation eddy viscosity model versus a dynamic structure one-equation model for the sub-grid stresses. The second example addresses the effects of numerical intake-valve opening strategy and local mesh refinement in the valve curtain.
\end{abstract}

Résumé - Benchmark de moteur de référence TCC-III pour la simulation aux grandes échelles (Large-Eddy Simulations, LES) de l'écoulement dans les moteurs à combustion interne - Un projet collaboratif est décrit, visant à caractériser le moteur TCC-III et à illustrer l'application de ces données pour l'évaluation de modèles de sous-maille et des détails de simulation des soupapes sur la fidélité de simulations aux grandes échelles. Le TCC-III est un moteur à allumage commandé 4 temps à deux soupapes et à culasse et piston plats, et il est équipé d'un cylindre en quartz donnant un accès optique maximal qui permet des mesures par vélocimétrie par image de particules (Particle Image Velocimetry, PIV) rapide; le TCC-III présente de nouveaux sièges de soupapes et un système d'admission modifié par rapport aux configurations précédentes. Le présent travail représente une extension d'une étude précédente à un régime moteur de $800 \mathrm{tr} / \mathrm{mn}$ et à une pression de collecteur d'admission de $95 \mathrm{kPa}$, pour laquelle un modèle $L E S$ de viscosité turbulente à une équation avait donné des prédictions qualitatives et quantitatives précises de la moyenne d'ensemble du champ de vitesse et de sa fluctuation pendant l'admission et la phase de compression. Dans le présent travail, 
les mesures expérimentales ont été acquises avec une variation paramétrique du régime moteur et de la pression absolue du collecteur d'admission, afin d'évaluer la capacité des modèles $L E S$ sur une gamme de conditions opératoires d'intérêt pratique. Le présent article met l'accent sur la répétabilité et la précision des mesures PIV, acquises à $1300 \mathrm{tr} / \mathrm{mn}$, à deux pressions collecteur admission différentes $(95 \mathrm{kPa}$ et $40 \mathrm{kPa}$ ), et réalisées dans plusieurs plans de visualisation et à différents angles vilebrequin. Deux exemples sont fournis, illustrant l'application de ces données au développement du modèle LES. Dans un exemple, les données expérimentales sont utilisées pour distinguer les efficacités d'un modèle de viscosité turbulente à une équation par rapport à un modèle de structure dynamique à une équation pour les contraintes sous-maille. Le second exemple traite des effets de la stratégie numérique d'ouverture de la soupape d'admission et du raffinement de maillage local dans le rideau de soupapes.

\section{NOMENCLATURE}

\section{$\Delta$}

$\Delta P$

1-D

aTDCexh

BDC

CA

CAD

cc

$\mathrm{CCV}$

$\mathrm{COV}$

CR

CFD

DSOE

$\mathrm{dt}$

EVC

EPL

EVO

FOV

GM R\&D

HCCI

IC

ICE

IMEP

IVC

IVL

IVO

LES

MAP

PIV

RANS

RMS

SGS

TCC

TDC

UM
Grid filter size

Pressure differential

One dimensional

After Top Dead Center exhaust

Bottom Dead Center

Crank Angle

Crank Angle Degree

Cubic centimeter

Cycle-to-Cycle Variation

Coefficient Of Variance

Compression Ratio

Computational Fluid Dynamics

Dynamic Structure One-Equation

Laser pulse separation

Exhaust Valve Closing

Exhaust valve Peak Lift

Exhaust Valve Opening

Field Of View

General Motors Research and Development

Homogeneous Charge Compression Ignition

Internal Combustion

Internal Combustion Engine

Indicated Mean Effective Pressure

Intake Valve Closing

Intake Valve peak Lift

Intake Valve Opening

Large-Eddy Simulation

Manifold Absolute Pressure

Particle Image Velocimetry

Reynolds-Average Navier Stokes

Root Mean Square

Sub-Grid-Scale

Transparent Combustion Chamber

Top Dead Center

University of Michigan

\section{INTRODUCTION}

Reynolds-Average Navier Stokes (RANS) simulation of reciprocating Internal Combustion Engine (ICE) combustion has matured to be a valuable tool for engineering design. This has been especially true for evaluating the averagecycle behavior of new engine concepts [1]. With increased computational capabilities, more details, such as cyclic variability (Cycle-to-Cycle Variation, CCV) can be addressed using multi-cycle Large-Eddy Simulation (LES), that has been evolving since the 1990s [2]. Since then, LES has been used to simulate flow and combustion in modern engine concepts such as four-valve pent-roof spark-ignition, Diesel, and HCCI engines [3-9]. These simulations of comprehensive and complex engine architecture are useful not only to guide engine development but also to identify the needed improvements in the LES approaches. In particular, for computational efficiency and cost considerations these simulation approaches must employ practical meshes and make simplifying assumptions, which include sub-models to describe processes below the resolved spatial or temporal scales. The accuracy of the sub-grid-models (Sub-GridScale, SGS), the numerical schemes in use, and more, have an impact on how well the in-cylinder processes can be simulated. These computations thus rely on accurate experimental data to identify the underlying physics and benchmark the simulation results. Only with accurate and repeatable experimental data is it possible to achieve a meaningful assessment and validation of the simulations. With this purpose in mind, the Transparent Combustion Chamber (TCC-0) engine was originally designed (circa 1990), built, and used for more fundamental investigations of the in-cylinder flow and combustion CCV using the then nascent Particle Image Velocimetry (PIV). The engine design was intended to provide benchmark data at the next logical level beyond the Imperial College data [10], adding essential features of ICE operation such as complete charge transfer processes, continuous operation, and combustion. Complementing the more recent LES calculations noted above, there are 
experimental data available from measurements within motored and fired four-valve pent roof engines [11, 12].

The TCC engine was resurrected in 2010 in the TCC-II version, to renew the fundamental investigation of $\mathrm{CCV}$ using experiments in conjunction with the evaluation of three different LES approaches [13]. The rationale to revert to this engine configuration was based on the original design philosophy. In particular, the geometry was purposefully chosen to be simple for ease of computational gridding, and optimized for optical access to the entire combustion chamber. In addition, the two-valve, pancake chamber design with a large piston-diameter to valve-diameter ratio produces extremely large-scale flow CCV when compared to the more naturally directed flow of a 4-valve pent roof design. The intent was to create an extremely large flow $\mathrm{CCV}$ that would be obviously detectable and an extreme test for simulations. It was used in its original configuration, the TCC-0, for experiments prior to 2000 [14-17]. The TCC-II ${ }^{(1)}$ configuration had the same engine geometry (refer to Tab. A1 of Appendix A) but a different intake system, exhaust system, and valve seat (two angles) compared to the TCC- 0 . The experimental results from the TCC-II configuration were useful for establishing the LES-toexperimental data-comparison protocols, to identify desired improvements in the hardware and operating procedures, and to assess the impact of engine and system imperfections on the in-cylinder flow [18-20]. Based on the TCC-II studies, new results are reported here from a third configuration, TCC-III, which has refurbished valve hardware and the intake/exhaust systems upgraded for fired testing. Also, the TCC-III data are significantly more repeatable and with expanded operating conditions as listed in Tables A2 and A3, respectively. Chronicles of the TCC engine versions and cross references to the corresponding publications can be found under http://deepblue.lib.umich.edu/handle/2027.42/108382.

The purpose of this paper is twofold. First, to document the motored experimental data and, second, to show examples of its use to guide the setup of LES and selection of sub-models to best capture experimentally observed flow conditions. To this end, the accuracy and test-to-test repeatability of the intra-cycle, high-speed motored pressure and PIV velocity data is documented. Then it is demonstrated how the data is used to make informed selections of LES SGS models and local mesh refinement efforts in the valve curtain. Given their frequent use, an eddy viscosity model and a dynamic structure model were chosen here for illustration. It is important to assess simulation performance for a range of operating conditions to avoid optimization or tuning of simulation settings to one condition but not gaining

\footnotetext{
${ }^{1}$ The TCC-I configuration did not exist in hardware but was a simulationonly geometry identical to the TCC-II hardware, except for utilizing a 45-degree, single-angle valve seat.
}

insight into the fidelity of reproducing different conditions. Two operating conditions will be highlighted here to illustrate how changes in intake manifold pressure affect the filling dynamics of the cylinder and how the simulations pick up this process. Conceptually, it is expected that a dynamic structure-based subgrid treatment would perform better than a simple eddy viscosity model in handling the flow around the valves and the resulting strong velocity gradients [8] in the intake 'jet' flow. Encouraging results that point to this led to investigations of increasing the mesh resolution around the valves to better capture the dynamics of the valve opening and closing events; this resulted in higher accuracy for the digital nature of valving events in CFD.

The experimental flow and pressure data acquired in this study is available upon request, while the geometry of the TCC-III engine and the GT Power model can be downloaded at http://deepblue.lib.umich.edu/handle/2027.42/108382 with the purpose of helping the engine CFD community to develop more accurate flow models.

\section{EXPERIMENTAL SETUP AND PROCEDURES}

\subsection{Engine Systems}

The UM (University of Michigan) TCC-III optical engine used here is a spark-ignition 2-valve, 4-stroke, pancake shape combustion chamber engine with a geometrical compression ratio of 10:1 and bore $\times$ stroke of $92 \times 86 \mathrm{~mm}$ (Fig. 1). It is equipped with a full quartz cylinder and a $70 \mathrm{~mm}$-diameter flat quartz piston window. Geometry and valve timings are provided in Table A1.

The TCC-III configuration has hardware upgrades from the TCC-II configuration. The TCC-III engine was refurbished with new hydraulic valve lifters, new valves (identical design), and new four-angle valve seats. Optical methods were established to determine the valve opening and closing times. The improvements were made in response to TCC-II simulation and experimental studies that revealed the need for more repeatable and better-documented valve events. The intake and exhaust systems are now prepared for firing tests as shown schematically in Figure 2a. Both a gaseousfuel and a nitrogen-dilution critical-orifice metering systems have been added. Flame arrestors have been added at the plenum inlets/outlets and water-cooled exhaust-pressure transducers were installed. The fuel and dilution systems were connected during the motored tests presented here, in order to sustain the same intake/exhaust system wave dynamics with fired operation (not presented here). Thus, new engine geometry files are required both for the LES and 1-D (GT Power) simulations of the TCC-III engine. Detailed geometry, stl, .igs, and the full GT Power model along with large experimental data sets (pressure and velocity) are 


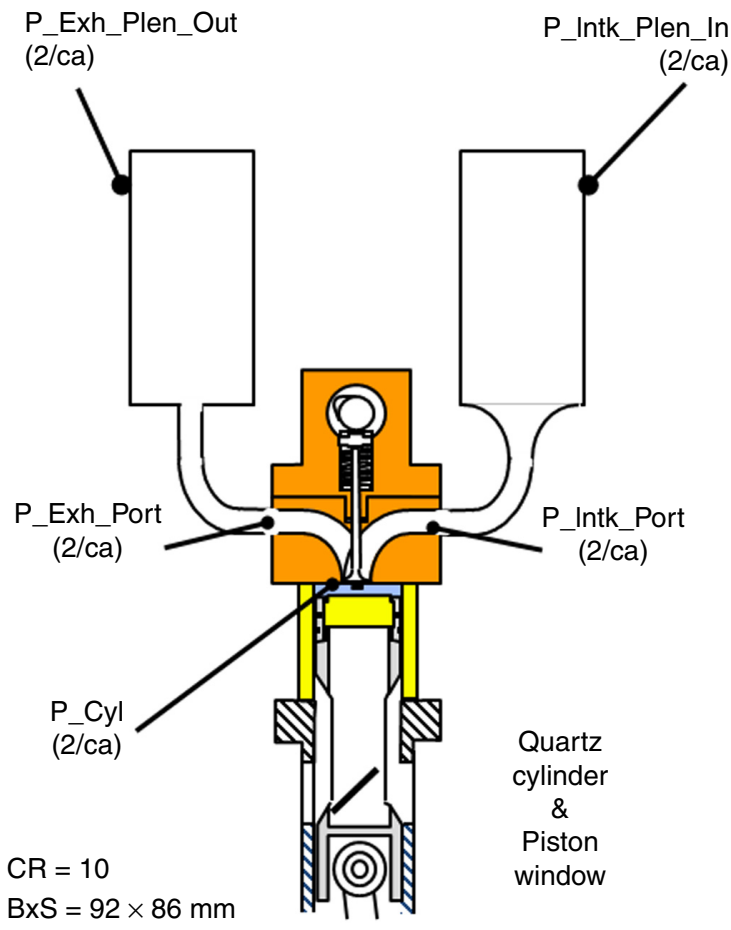

Figure 1

Schematic of TCC Engine and high-speed pressure measurement locations.

available for download at http://deepblue.lib.umich.edu/ handle/2027.42/108382.

The intake and exhaust systems were instrumented with high-frequency piezo-resistive absolute-pressure transducers (Kistler 4007B in the intake and Kistler 4049A in the exhaust (water cooled)) to record the intra-cycle pressure every $0.5 \mathrm{CAD}$ and to determine $\mathrm{CCV}$ at the desired boundary conditions (Fig. 1). The intake plenum and runner, exhaust runner, and cooling water were electrically heated to the $45^{\circ} \mathrm{C}$ intake-air operating point to minimize temperature gradients in the air flow. The engine was warmed up and transducer zero-drift adjusted to barometric standards prior to each test. The uncertainty of the transducers is estimated to be $0.1-0.2 \%$ of full scale output $= \pm 0.5-1 \mathrm{kPa}$ for the $500 \mathrm{kPa}$ transducers in use. A closed intake system (not open to atmospheric pressure) was used with the air flow metered using critical flow nozzles and monitored with a redundant laminar-flow meter upstream of the nozzles. Estimated precision and accuracy are $0.1 \%$ and $0.5 \%$ of the measured value respectively.

A comprehensive table of all transducers' accuracy and precision is available with the posted data. The intake system was checked for leakage, after engine cleaning, prior to each test. The piston-ring blow-by was measured to be less than
$1 \%$ at $95 \mathrm{kPa}$ MAP. The piezo-electric cylinder pressure transducer was pegged using a $10 \mathrm{CAD}$ average at 140 aTDCexh, where the 1-D model predicted that pressures in the intake plenum, the intake port, and in the cylinder should all be at the same value. A back-pressure valve just downstream of the flame arrester was used to maintain the exhaust plenum operation set point at $101.5 \mathrm{kPa}$ average pressure.

Operating procedures were instituted to assure engine operation repeatability during the six months the data was acquired, including charting of the run-time control parameters. The engine was motored for 15-20 minutes to achieve conditions that were nearly in steady-state, and repeatable. The temperature of the quartz cylinder outside-surface at mid-stroke was brought to $40 \pm 4^{\circ} \mathrm{C}$, depending on operating condition. At run time, the engine speed, delivered air mass flow, and the average intake and exhaust pressures were controlled. The average port pressures, peak cylinder pressure and IMEP were monitored to ensure the engine trapped mass was repeating. Table A2 gives an overview of test-to-test variation of several critical engine parameters and their stability throughout each run.

The test-to-test repeatability of the engine operation is illustrated in Figure 3a, where differences between the individual-test average (over hundreds of cycles) and the average of all tests (discrepancy) are quantified. Here, the discrepancy is plotted since the differences are too small to discriminate on a full-scale plot of the absolute values. The test-to-test deviation in the plenum and ports is much less than $0.5 \%$. In-cylinder pressures are similar through much of the cycle but deviate up to $2 \%$ through during the valve overlap and early part of the intake stroke ( -45 to 90 aTDCexh). At 2\% these discrepancies are still small compared to differences shown between the simulations and the data (Fig. 3b), and any discussion of their cause would be pure speculation at this time. The percent discrepancy for the $40 \mathrm{kPa}$ operation is higher due to the lower absolute value, but nominally is of the same order as the $95 \mathrm{kPa}$ operation. Note that data set names are included in many figures throughout this paper to facilitate the connection with the shared data sets (Tab. A3).

\subsection{PIV Measurements}

The PIV measurements were recorded successively in the four planes shown in Figure 4, every $5 \mathrm{CAD}$ for at least 235 consecutive cycles per test. The Field Of View (FOV) is restricted by the piston window to approximately the center $70 \mathrm{~mm}$ for both vertical and horizontal cutting planes. In both the $z=-5 \mathrm{~mm}$ and $z=-30 \mathrm{~mm}$ planes the light sheet is brought into the cylinder from the positive $x$-direction. Thus, during intake stroke a major part of the FOV is blocked by the intake valve and its shade for the $z=-5 \mathrm{~mm}$ images. The vertical cutting planes have a FOV from piston to 


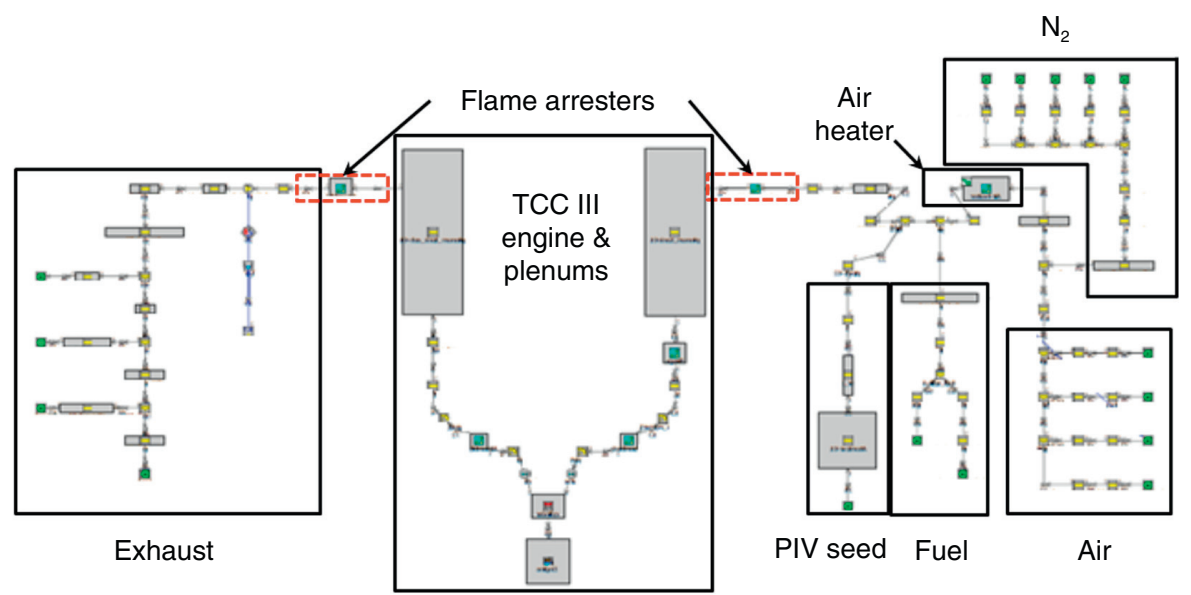

a)

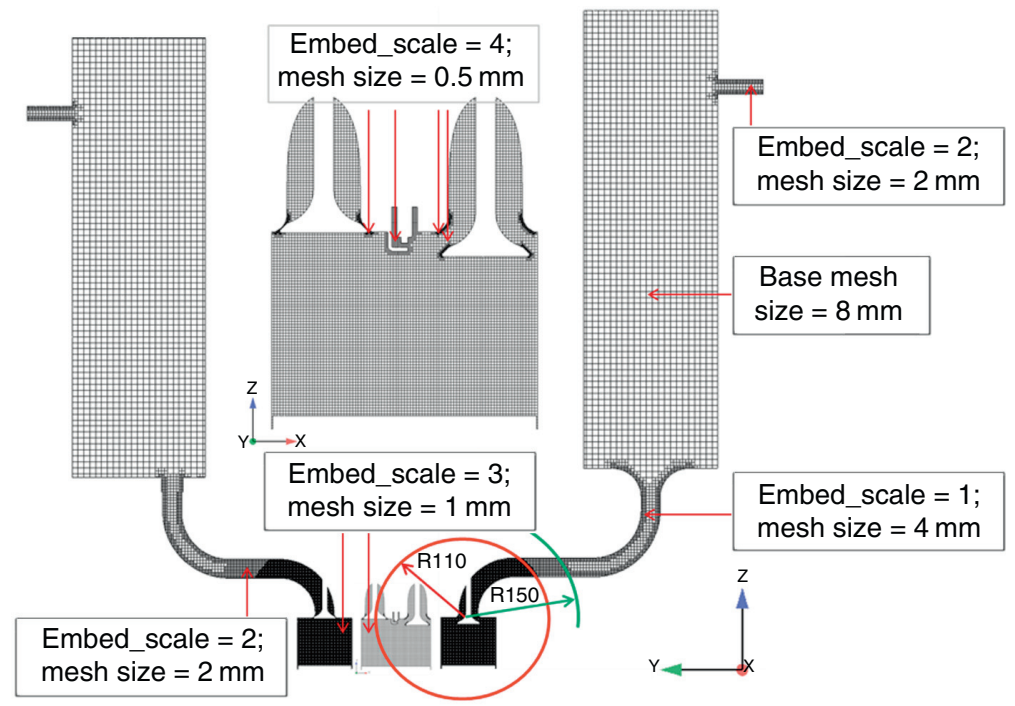

b)

Figure 2

Schematic of the engine systems and simulation domains. a) 1-D Model illustrating major intake and exhaust sub systems. b) LES computational domain and meshing.

cylinder head with an approximate width of just below $70 \mathrm{~mm}$. A summary is provided in Table A3. Images were recorded using a monochrome high-speed camera (Vision Research, Phantom v1610) with a $1280 \times 800$ pixel sensor and 12-bit dynamic range. Silicone-oil droplets $(1 \mu \mathrm{m})$ were added to the intake air and illuminated by a high-repetition-rate dual-cavity frequency doubled Nd:YLF laser (Darwin Duo, Quantronix). The light sheet thickness was 2.0-2.4 $\mathrm{mm}$ in the various cutting planes adjusted based on the in-plane resolution set by the $210 \mathrm{~mm}$ Nikon Micro-Nikkor ED lens with an aperture of $\mathrm{f} / \#=5.6$ and the distance to the imaging plane.

Image processing began by remapping the raw images to eliminate the non-linear grid distortions caused by the cylinder and thick piston window. A $3^{\text {rd }}$-order polynomial fit was used for all data recorded in a vertical plane and a linear fit for data captured in the horizontal planes. Then a sliding minimum intensity subtraction was performed to reduce reflections from cylinder head, valve edges and spark plug. All vector fields were calculated using a commercial PIV code (DaVis 8.x, LaVision) employing a decreasing interrogation window size $(1 \times 128 \times 128$ pixel, $50 \%$ overlap then $2 \times 32 \times 32$ pixel, $50 \%$ overlap). The final interrogation window spot size is 2.5 to $2.8 \mathrm{~mm}$ with a vector separation of 1.25-1.4 mm. The percentage of first-choice vectors of the experimental data shown here is $>98 \%$, meaning that less than $2 \%$ of the vectors of the instantaneous flow fields have been lower than $1^{\text {st }}$ choice or have been interpolated. 

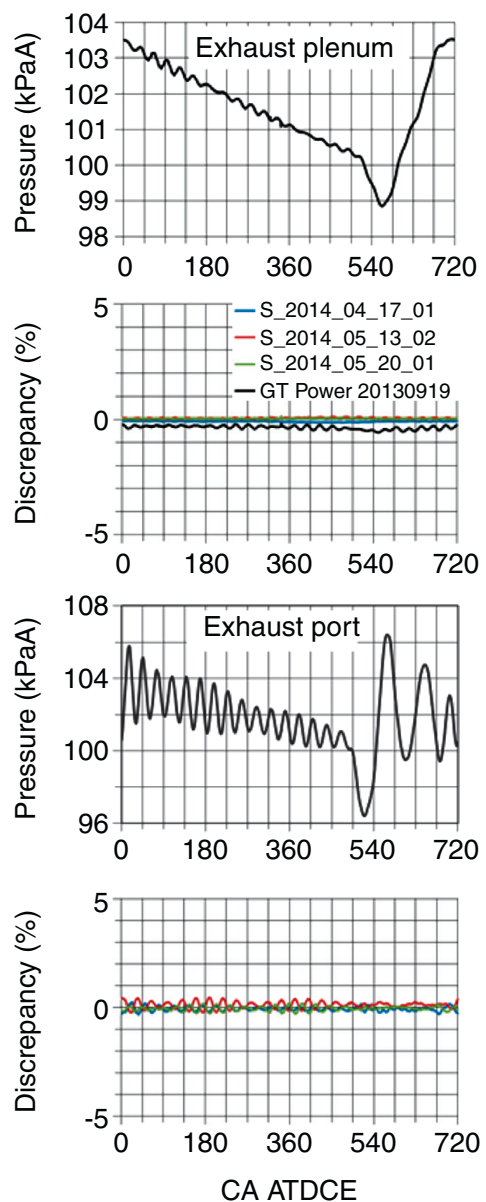

a) Test-to-test repeatability of test averages at $1300 \mathrm{rpm}, 95 \mathrm{kPa}$
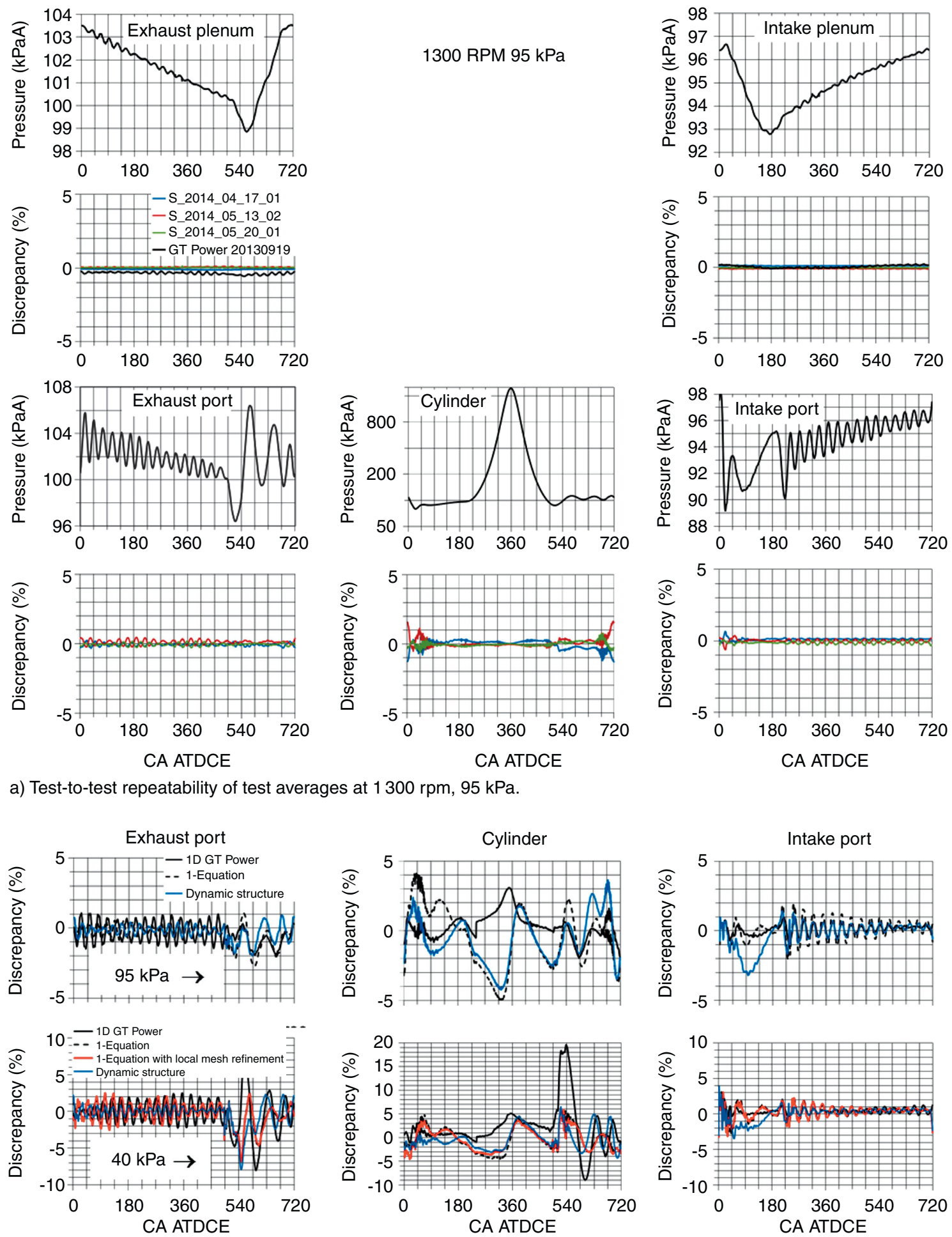

b) Simulation-to-measured pressures discrepancies for 95 and $40 \mathrm{kPa}$.

Figure 3

Experimental pressure test-to-test repeatability compared to simulation-to-measured pressures. a) Three test average pressure traces (in $\mathrm{kPaA}=$ $\mathrm{kPa}$ absolute) and discrepancy of the individual test towards this average (and GT Power for plenums). b) Discrepancy of simulations at 40 and $95 \mathrm{kPa}$ MAP for port and cylinder pressures. 


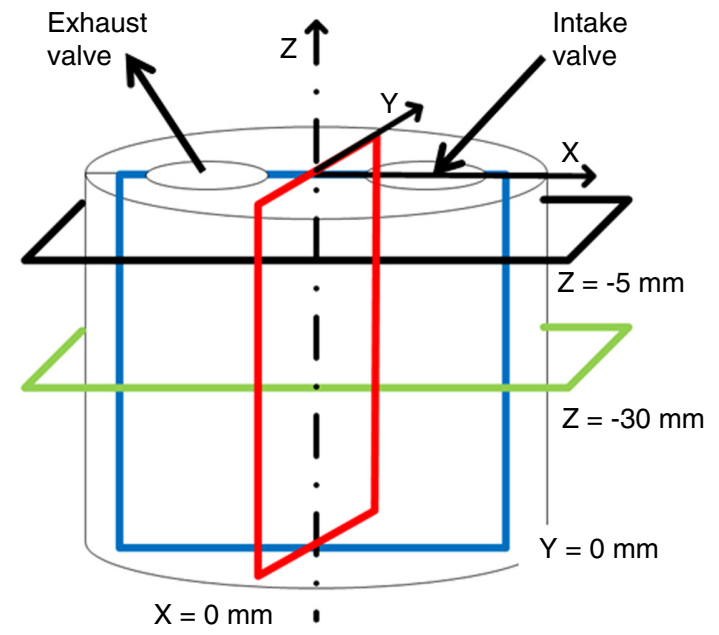

Figure 4

Laser-sheet locations and definition of coordinates. All laser sheets and fields-of-view are truncated by the $70 \mathrm{~mm}$ diameter piston window.

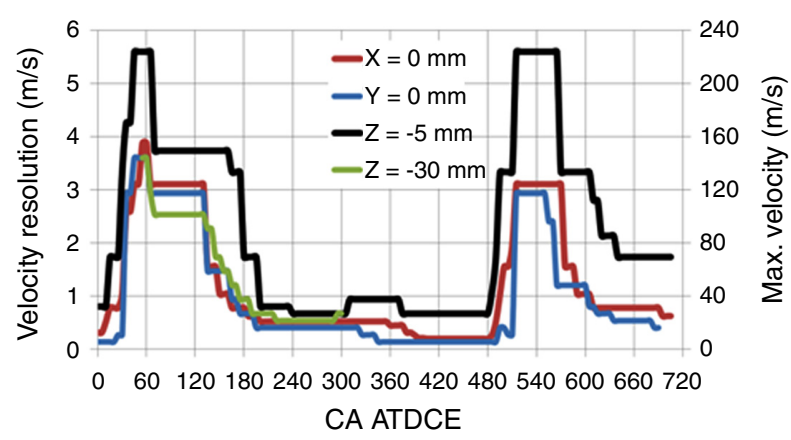

Figure 5

PIV velocity resolution based on 0.2 pixel velocity resolution and maximum velocity.

The velocity dynamic range of PIV is limited to roughly 40:1. The upper limit is defined by a maximum particle image displacement of 8 pixels (one quarter of the interrogation window) [21] and lower limit of 0.2 pixels (sub-pixel displacement detection) is based on a previous analysis performed under optical engine conditions [22, 23]. To make best use of this velocity range, the laser-pulse separation, $\mathrm{d} t$, was adjusted on a per CAD base during the cycle [20]. Here, $\mathrm{d} t$ ranged from $3 \mu$ s during the intake and exhaust strokes when velocities are high, to $80 \mu$ s around TDC compression when velocities are lowest. For the $z=-5 \mathrm{~mm}$ plane, out-of-plane velocities were very high and the laser pulse separation time dt needed to be shortened accordingly to avoid out-of-plane particle-pair losses. Figure 5 shows the velocity error (resolution) and maximum velocity as a function of crank angle based on the 0.2 pixel detection limit and 8-pixel maximum, respectively. Figure 5 can then be used to estimate the experimental error, which is important when making quantitative comparisons with simulation data.

Experience tells that measurements in engines can show substantial test-to-test variability and therefore it is essential for LES validation to quantify the test-to-test repeatability of the velocity measurements. For this assessment and to illustrate this here, the ensemble average velocity was sampled along the centerline of the cylinder $(x=0, y=0)$ for the $x-z$ and $y-z$ planes as shown in Figure 6. The planes required different optical setups, and the three tests were taken at early, middle, and late times during the six-month measurement campaign. As with the pressure, the velocity repeatability will be shown to be much better than the discrepancies observed between experiments and simulations.

The quality of convergence of the ensemble-averaged velocity and ensemble-standard deviation of velocities are a function of the number of cycles used to compute the values, the location, and crank angle. To illustrate this, the coefficients of variance COV at 100 and 300 CAD aTDC are shown in Figure 7a, which can be used as a metric to estimate the deviation of the calculated mean flow to the converged mean. Regions of low COV are expected to converge faster than high $\mathrm{COV}$ areas. For a more in-depth discussion the convergence at point $\mathrm{A}$ is examined in greater detail and those results are shown in Figure $7 \mathrm{~b}-\mathrm{d}$. In Figure 7b, the normalized ensemble average velocity magnitude of different-sized sub-samples is shown for consecutive and randomized cycles. Using randomized sub-samples is an important statistical check since it can be assumed that there might be some correlation in flows from one cycle to the next. In particular, due to slow drifts in the mean flow with time (shown in Fig.7d), caused by changes in swirl ratio [19], the variations are interdependent. The solid black lines show the estimated error in the mean that was determined as sample size divided by COV squared as proposed by [24] and indicate about the $80 \%$ confidence interval. Doubling the error range (dashed lines) shows about the entire range for randomized data suggesting that for randomized sub-samples, the statistical expectations are confirmed. Despite shifts in the mean flow, the range of the expected error in standard deviation follows the correlation of two over the square root of the sample size minus one as suggested in [24]. The normalized probability density functions of the two velocity components at point A follow approximately a normal distribution. The mean was subtracted from $V_{x}$ and $V_{z}$ and each component was divided by its standard deviation in order to compare both in the same plot to the standard normal distribution (mean $=0$, standard deviation $=1$ ).

To illustrate the statistical error of the measurements as a function of crank angle, Figure 8 plots both the coefficient of variation $(\mathrm{COV}=$ spatial average of ensemble RMS divided by spatial average of ensemble average) and the statistical 


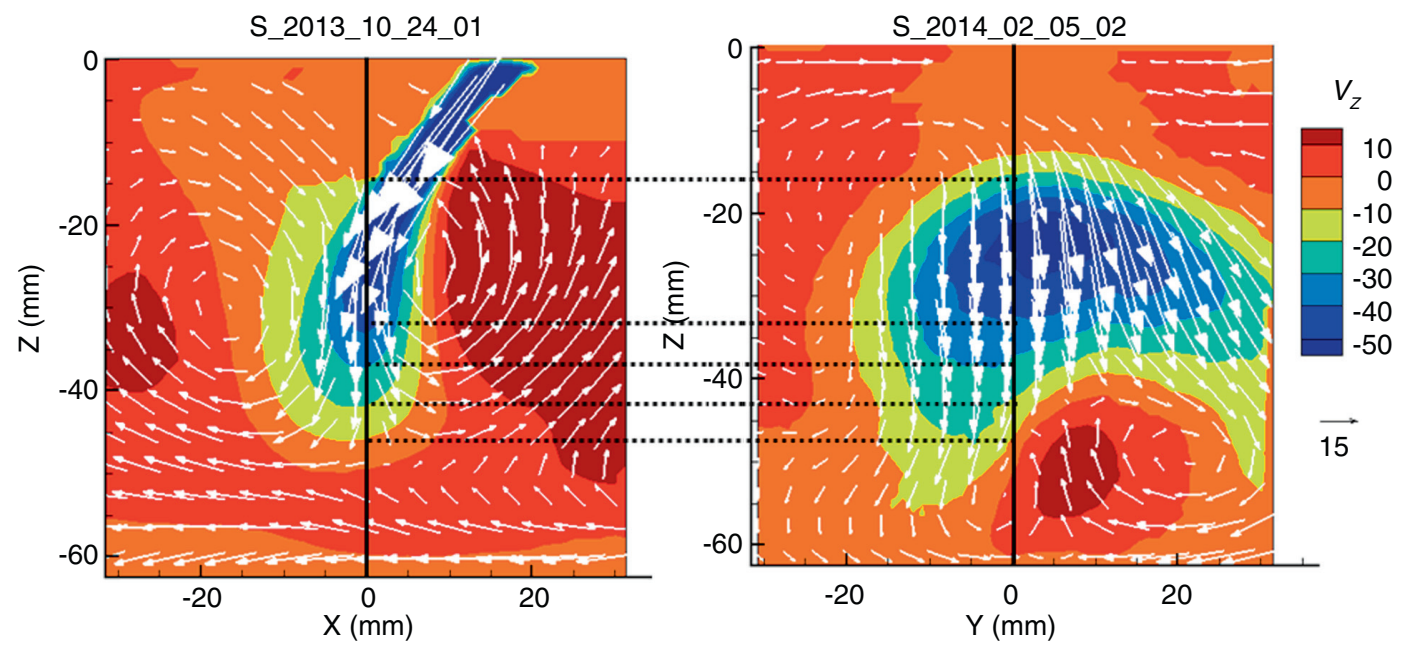

a) Comparison of ensemble averaged $V_{z}$ contour plots between two different tests in two different planes
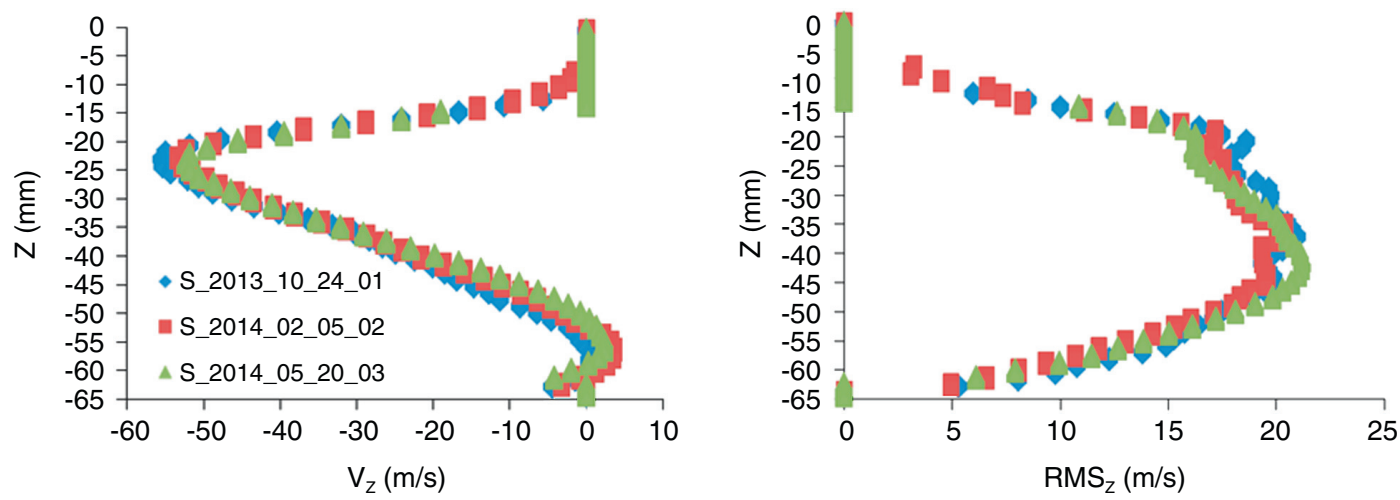

b) Comparison of ensemble averaged $V_{Z}$ (left) and $\mathrm{RMS}_{\mathrm{Z}}$ (right) of three runs along $\mathrm{Z}$ axis

Figure 6

Ensemble-averaged $V_{z}$ and $R M S_{z}$ at $100 \mathrm{CAD}$ ATDCE from the series' first test (S $2013 \quad 1024 \quad 01, y=0,240$ cycles), a mid series test at an orthogonal view (S_2014_02_05_02, $x=0,235$ cycles), and the series' last test (S_2014_05_20_03,y $=0,3035$ cycles).

error (COV divided by square root of sample size) at each crank angle. For most of the cycle the estimated averagevelocity error is below $10 \%$, with the exception of both top dead centers where an error of $18 \%$ can be expected. These errors are always less than $7 \%$ of the COV, which is a measure of $\mathrm{CCV}$.

\section{ID AND LARGE-EDDY SIMULATIONS}

\subsection{LES Methods and Models}

LES at an engineering-level were conducted with the CONVERGE code [25] at GM R\&D. Here, the computational domain includes the intake port and plenum, the cylinder, and exhaust port and plenum. 1D simulation results are used to define the initial and boundary conditions. Crank angle based total pressure and temperature are applied as inlet boundary conditions. Crank angle based static pressure is used as the outlet boundary condition. An orthogonal structured finite volume method with boundary cut-cell mesh and pressure-based time-implicit compressible schemes was employed, yielding secondorder momentum and first-order space and time accuracies. Turbulent kinetic energy at the walls is replaced by subgrid kinetic energy, approximated based on the sub-grid velocity as suggested in [26]. The Werner and Wengle wall model was used for the treatment of the sub-grid kinetic energy at the walls [27]. The mesh size in the near wall region is in the range of $y+=10$ to 110 . 
100 CAD ATDCE

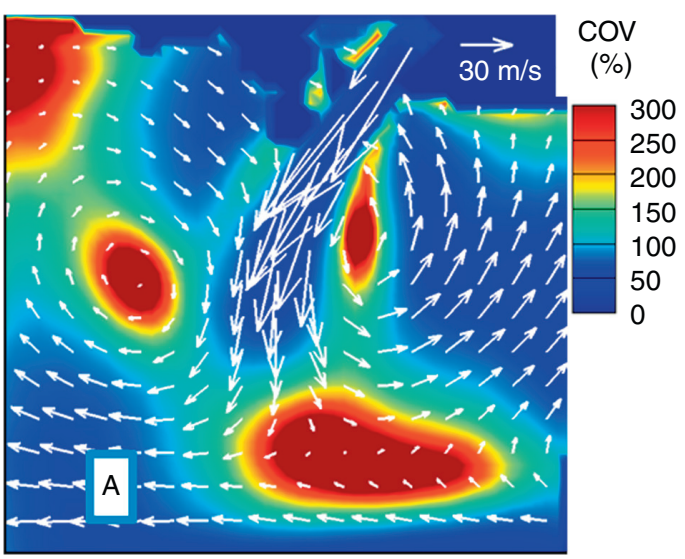

a)

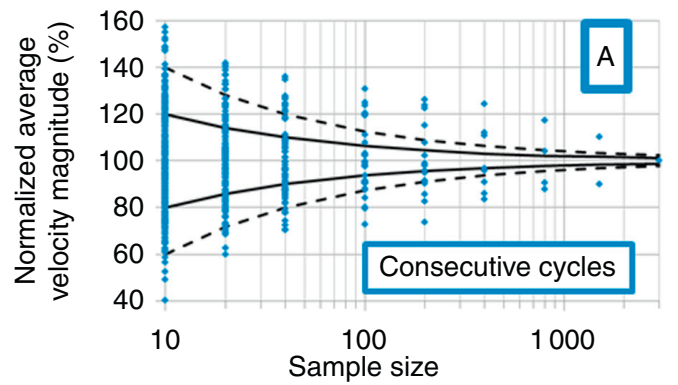

b)

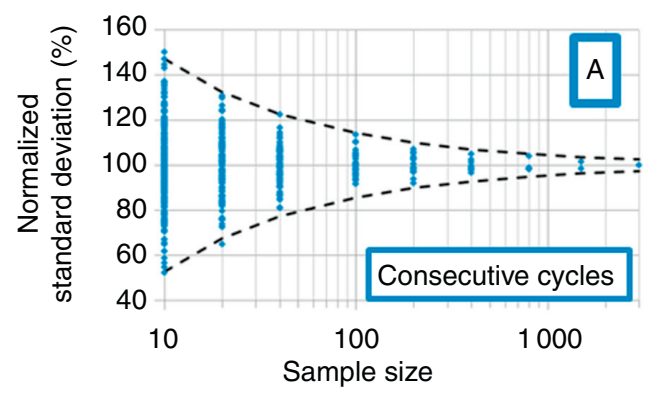

c)

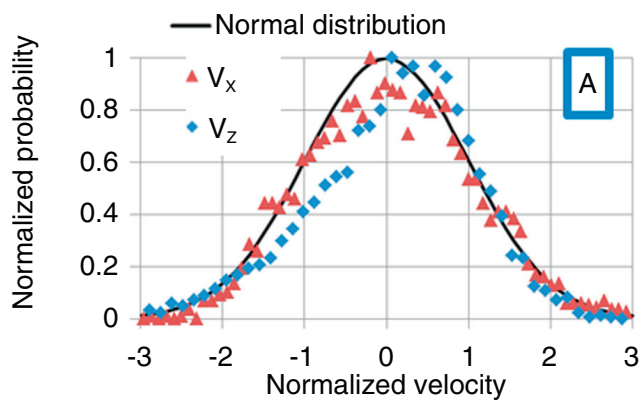

d)

\section{CAD ATDCE}
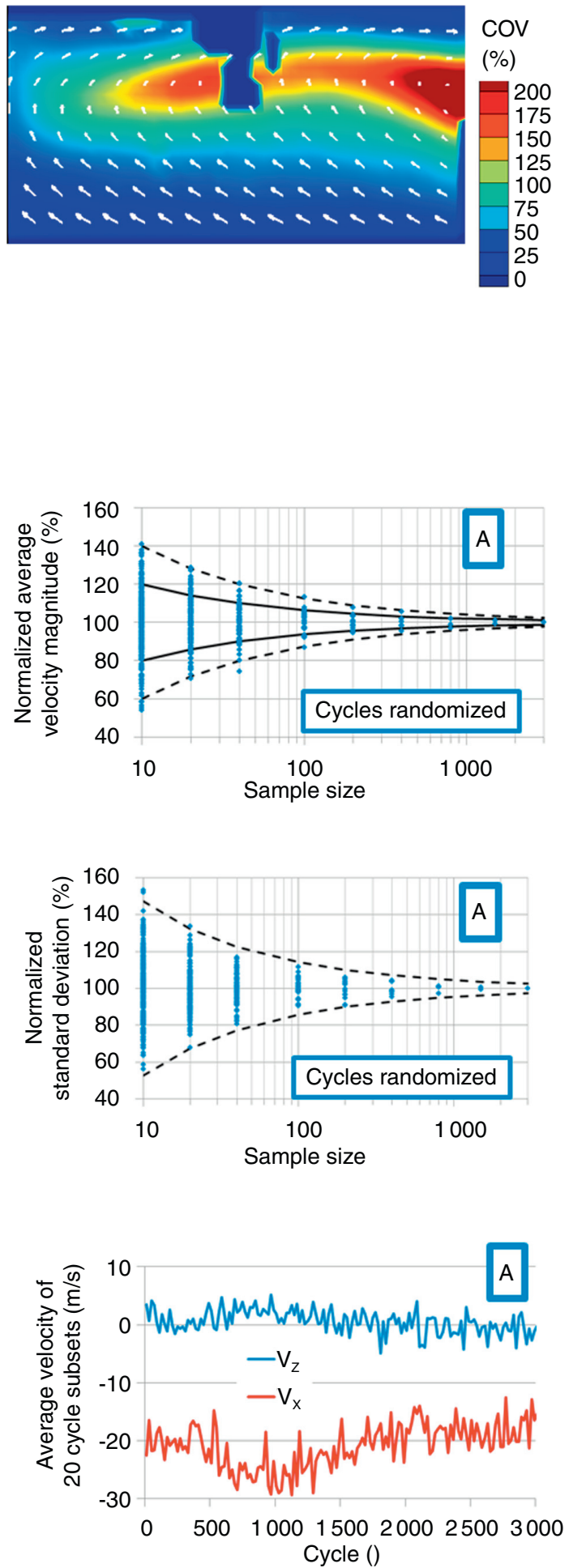

Figure 7

Sample-size convergence of ensemble average velocity and of standard deviation. All data are normalized to the average of a 3000 -cycle run. a) Color maps of coefficient of variance (COV) at 100 and 300 CAD ATDCE (vectors represent ensemble mean flow field). b) Distribution of subsample normalized average velocity magnitudes at point A as function of sample size (cycles). c) Distribution of sub-sample normalized standard deviation of velocity magnitudes at point A as function of sample size (cycles). d) Probability distribution of velocity magnitude follows normal distribution (3035 samples); Temporal evolution of 20 cycle sub-sample averages of both velocity components. 

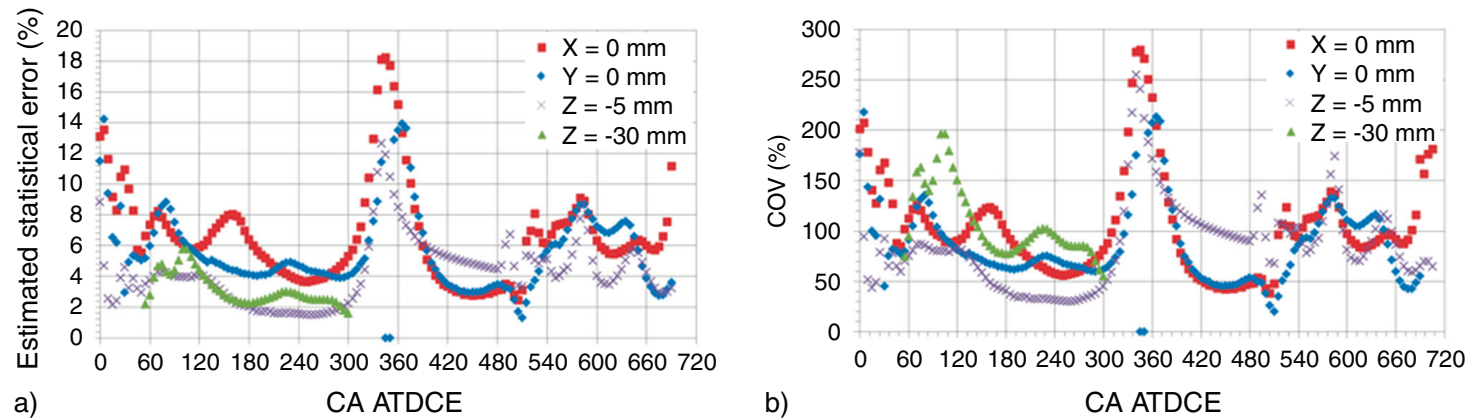

Figure 8

Ensemble-averaged velocity a) statistical error and b) COV computed from spatial-average of ensemble average velocity and ensemble RMS (cyclic variability).

For the present work, two LES sub-grid scale turbulence models were used:

- one-equation eddy viscosity model [28, 29],

- Dynamic Structure One-Equation model (DSOE) $[30,31]$.

\subsection{One-Equation Eddy Viscosity Model}

The one-equation eddy viscosity model closes the sub-grid stress tensor with a turbulent viscosity. Model constants are required for the turbulent viscosity and the dissipation term. The model adds a transport equation for the sub-grid kinetic energy to the energy equation. The sub-grid kinetic energy is then used in modeling the turbulent viscosity and is given by:

$$
\frac{\partial k}{\partial t}+\overline{u_{i}} \frac{\partial k}{\partial x_{i}}=-\tau_{i j} \frac{\partial \overline{u_{i}}}{\partial x_{j}}-\epsilon+\frac{\partial}{\partial x_{i}}\left(\frac{v_{t}}{\sigma_{k}} \frac{\partial k}{\partial x_{i}}\right)
$$

Here, the sub-grid kinetic energy is determined as:

$$
k=\frac{1}{2}\left(\overline{u_{i} u_{i}}-\overline{u_{i}} \bar{u}_{i}\right)
$$

The turbulent viscosity for the one-equation model is given as:

$$
v_{t}=C_{k} k^{1 / 2} \Delta
$$

where $\Delta$ the grid filter which is set to the local cell size. Note that the turbulent viscosity is a function of grid size so that in the limit of fine resolution the turbulent viscosity goes to zero. The turbulent viscosity can be 'tuned' by adjusting the constant $C_{k}$ in the above expression and a value of 0.05 was used for the present work. The sub-grid dissipation is given as:

$$
\epsilon=C_{\varepsilon} k^{3 / 2} / \Delta
$$

The sub-grid dissipation can also be 'tuned' by adjusting the constant $C_{\varepsilon}$ in the above expression. Here, the value was set to 1 .

\subsection{Dynamic Structure One-Equation Model}

The DSOE model is also a kind of one-equation LES model. The model for the sub-grid stress tensor does not use a turbulent viscosity concept but rather an attempt is made to model the sub-grid stress tensor more accurately (i.e., the sub-grid stress tensor cannot be accurately modeled with a turbulent viscosity). A dynamic approach is used to eliminate user-specified constants in the sub-grid stress tensor model. However, a dissipation model is still required that has a user-specified model constant.

To formulate a dynamic model, a second filtering operation, which is designated the test level filter, $\widehat{\Delta}$, is required. The test filter, $\widehat{\Delta}$, is typically twice the value of the grid filter, $\Delta$. The residual stresses based on single (grid) and double filtering (test) operations are defined by:

$$
\tau_{i j}=\left(\overline{u_{i} u_{i}}-\overline{u_{i}} \overline{u_{i}}\right)
$$

and

$$
T_{i j}=\left(\widehat{\overline{u_{i} u_{i}}}-\widehat{\overline{u_{i}}} \widehat{\overline{u_{i}}}\right)
$$

The grid level stress tensor and the test level stress tensor are related by the Germano identity [32]:

$$
L_{i j}=T_{i j}-\tau_{i j}=\left(\widehat{\overline{u_{i} u_{i}}}-\widehat{\overline{u_{i}}} \widehat{\widehat{u_{i}}}\right)
$$

Then the model for the sub-grid stress tensor becomes:

$$
\tau_{i j}=2 k\left(\frac{L_{i j}}{L_{i i}}\right)
$$


For improved fidelity of wall flows simulation when running the LES model with CONVERGE, the Werner and Wengle wall model [33] was enabled.

Orthogonal cubic meshes were automatically created at run time to avoid any variation in cell shape or size. Adaptive Mesh Refinement (AMR) can also be used to increase the effective grid resolution but was not enabled in the present study. The LES sub-grid stress tensor modeled in CONVERGE yields $2^{\text {nd }}$ order accuracy due to its central difference scheme.

A feature of the code called 'embed-sphere' was employed in all the LES calculations carried out at $G M$ $R \& D$, mainly to minimize the effect of mesh topology on the computed results and to enable better quantitative comparisons between various applications. An example is shown in Figure $2 \mathrm{~b}$ where the finest mesh $(0.5 \mathrm{~mm})$ is placed in the valve seat and spark plug regions while the coarsest mesh $(8 \mathrm{~mm})$ is placed inside the intake and exhaust plenums.

\section{RESULTS}

The results of the experimental effort provide a set of benchmark data for motored flows to guide setup and eventually allow validation of multi-cycle LES calculations. Having demonstrated the test-to-test repeatability of the engine operation and data, this section demonstrates one application of the measured data for LES development. It is important to assess simulation performance for a range of operating conditions to avoid optimization or tuning of simulation settings to one condition but not gaining insight into the fidelity of reproducing different conditions. Two operating conditions will be highlighted here to illustrate how changes in intake manifold pressure affect the filling dynamics of the cylinder and how the simulations pick up this process. Conceptually, it is expected that a dynamic structure-based sub-grid treatment would perform better than a simple eddy viscosity model in handling the flow around the valves and the resulting strong velocity gradients in the intake 'jet' flow. Encouraging results that point to this then also lead to investigations of increasing the mesh resolution around the valves to better capture the dynamics of the valve opening and closing events; this resulted in higher accuracy for the numerical nature of valving events in CFD. In this case study comparisons are made between the $1300 \mathrm{rpm} / 95 \mathrm{kPa}$ and $1300 \mathrm{rpm} / 40 \mathrm{kPa}$ operating conditions. Prior to comparing the in-cylinder velocity distributions, it is of value to compare the mass-flow and pressures between the measured and simulated data.

\subsection{Pressure Dynamics and Mass Flow}

The TCC-III intake system is closed, meaning that the intake is not open to the atmospheric pressure. Instead, the critical orifice flow meters deliver a fixed mass flow rate, $\dot{m}$, to the intake system and are adjusted to achieve the desire MAP. Thus, the intake plenum pressure fluctuates, since the plenum fills at fixed rate but empties according to the periodic flow rates of the engine's intake stroke. The pressure was measured at the intake plenum inlet and exhaust plenum outlet and modeled quite accurately by the 1-D simulation as was shown in Figure 3a. Table A2 shows that the measured average mass flow is within $2.4 \%$ of that of the 1-D simulation. LES results obtained with GT Power model boundary conditions and experimental boundary conditions do not show significant differences. Thus, the 1-D model results were used as the crank-angle dependent plenum-boundary conditions for the LES calculations. In general, this enables simulations for operating conditions or engine designs for which no experimental data are available.

Since the plenum inlet/outlet pressures are the inputs set at run time, only the intake port, exhaust port and in-cylinder pressures are metrics of the LES effectiveness. As with the experimental test-to-test variation, Figure $3 \mathrm{~b}$ quantifies the discrepancy of the phase-averaged pressures between the simulations (LES and 1-D) and measurements. Although the discrepancy is large compared to the test variability (Fig. 3a), the simulated intake port pressures are shown to be within $3 \%$ of the measured pressures during the intake stroke. The cylinder-pressure discrepancy is as much as $5 \%$ of the absolute values, but this is expected and acceptable due to the large dynamic range of the pressure transducer data.

The peak pressure and location of peak pressure are compared in Table A2 and shown to be within 7\% and 1 CAD for the GT Power simulation and $2.5 \%$ and 1 CAD for LES. Both differences are dominated by the trapped mass, although small differences can be due to the heat transfer (Woschni model) and blowby, which was not modeled here.

Figure 9a shows the measured pressure drop across the intake port, valves, and the in-cylinder volume, $\Delta P=P_{\text {Intake_Port }}-P_{\text {Cylinder }}$. The simulated 1-D mass flow through the valve, $\dot{m}$, and the valve lift are shown during the intake stroke (0-300 aTDCexh). The very good agreement between the 1-D simulation and measured $\Delta P$ (refer to dashed-line, Fig. 9b), provides confidence that the 1-D simulated mass flow is reasonably accurate. Figure 9a shows high intake mass flow rates with relatively low lift before $\mathrm{CAD} 60$, and negative flows during valve overlap (esp. $40 \mathrm{kPa}, \mathrm{CA}<30$ ) and between BDC and IVC. The importance of the mass-flow and lift during the early intake stroke will be discussed during the presentation of the velocity data. 


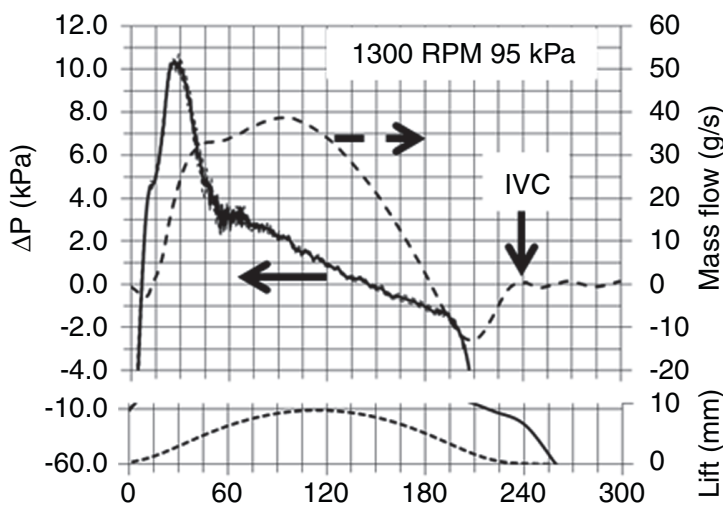

a)

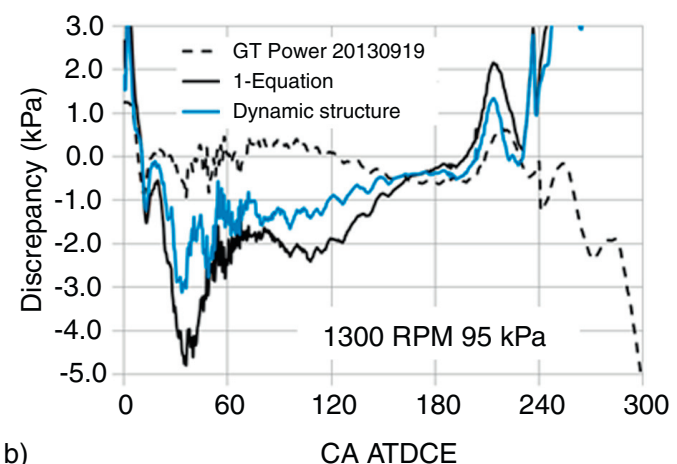

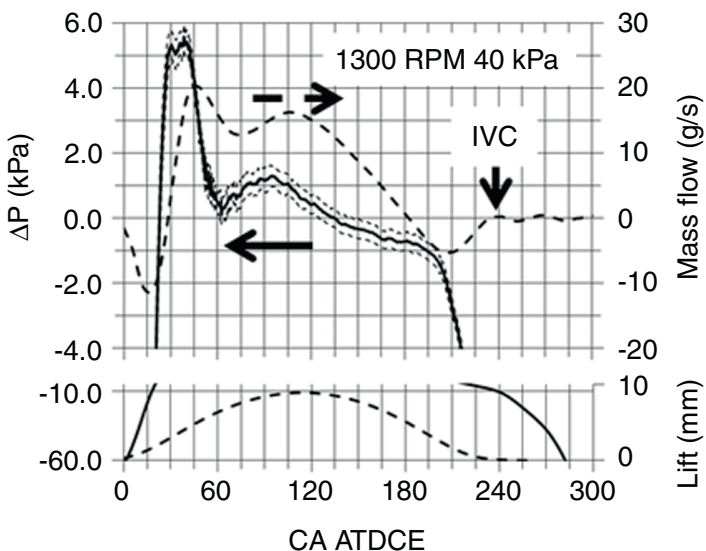

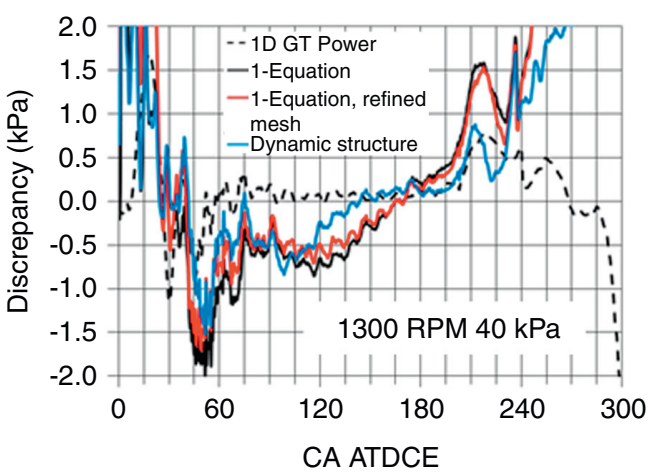

Figure 9

Comparison between the measured and simulated pressure drop across the port and valve $\left(\Delta P=P_{\text {IntakePort }}-P_{\text {cyl }}\right), 1$-D mass flow through the valve, and valve lift during the intake stroke; Note that in a) the bottom part of the $y$-axis is a continuation of $\Delta P$ for valve opening and closing. a) Measured $\Delta \mathrm{P}, 1-\mathrm{D}$ simulation of mass flow, and valve lift. b) Discrepancy between the measured and simulated $\Delta \mathrm{P}$.

\subsection{Velocity Data}

As an extension of the previous work at $800 \mathrm{rpm}, 95 \mathrm{kPa}[7]$, a goal of the present study was to develop the know-how of LES setup (sub-models/mesh refinement/valve timings etc.) pertaining to varying engine operating conditions of more practical relevance. The variation of intake manifold pressure is addressed as an example and explores predictive capabilities for $1300 \mathrm{rpm}, 95 \mathrm{kPa}$ and $1300 \mathrm{rpm}$, $40 \mathrm{kPa}$ in comparison to comprehensive PIV data taken in four cross sections (Fig. 4). LES predictions with OneEquation Eddy Viscosity and One-Equation Dynamic Structure models are compared to PIV measurements for various crank angle positions. For illustration purposes, results are described at $100 \mathrm{CA}$, corresponding to the intake jet flow, and $300 \mathrm{CA}$, corresponding to the compression flow. Cutting planes in all three orthogonal directions $(Y=0, X=0$ and $Z=-5$ and $-30 \mathrm{~mm}$ ) are considered to get a three-dimensional view of the flow field, though only results of the horizontal plane at $Z=-30 \mathrm{~mm}$ are discussed here. After a first look into the $1300 \mathrm{rpm}, 95 \mathrm{kPa}$ case and the lower MAP operating point (1 $300 \mathrm{rpm}, 40 \mathrm{kPa}$ ) is explored to identify differences in the flow that are expected from the observed pressure dynamics (Fig. 9).

Ensemble average velocity vector fields and ensemble RMS fields were visually compared side-by-side. Only the in-plane velocity components were considered for LES, because the PIV measurements provide only two velocity components. At every point in each plane, the ensemble average and ensemble RMS were calculated, over all cycles $n$, as follows in $\mathrm{m} / \mathrm{s}$ :

$$
\begin{gathered}
V_{\text {avg }}=\frac{1}{n} \sum_{i=1}^{n} V_{i} \\
V_{r m s}=\sqrt{\frac{1}{n-1} \sum_{i=1}^{n}\left(V_{i}-V_{a v g}\right)^{2}}
\end{gathered}
$$




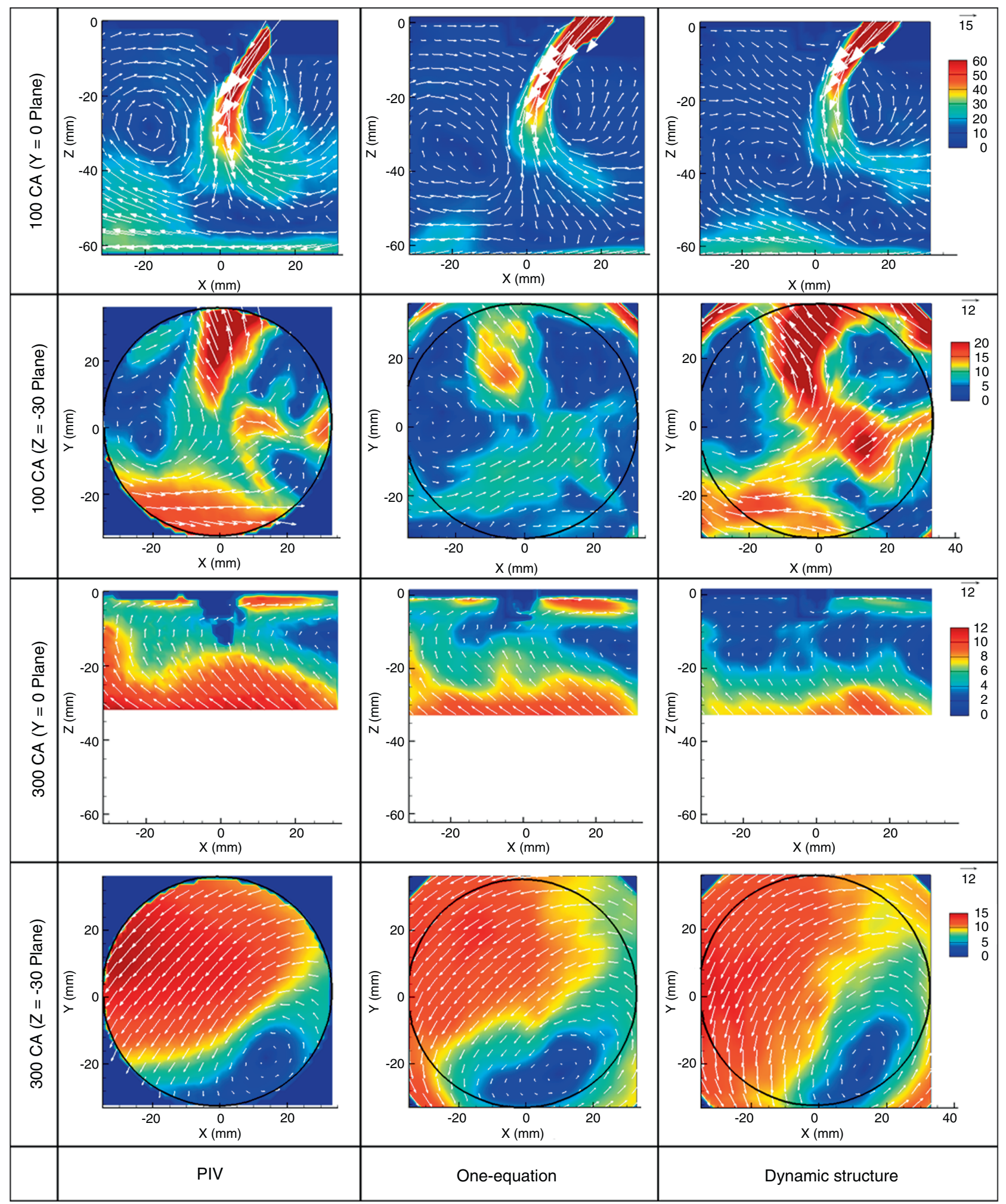

Figure 10

PIV and LES ensemble averaged mean flow velocities (velocity magnitude color-coded, in $\mathrm{m} / \mathrm{s}$ ) at various cutting planes and crank angle positions for $1300 \mathrm{rpm}, 95 \mathrm{kPa}$. The circles indicate the PIV FOV. Number of cycles used for ensemble average calculation: PIV $Y=0 \mathrm{~mm} \#=240$, PIV $Z=-30 \mathrm{~mm} \#=1157$, one-equation $\#=20$, dynamic structure $\#=20$. 


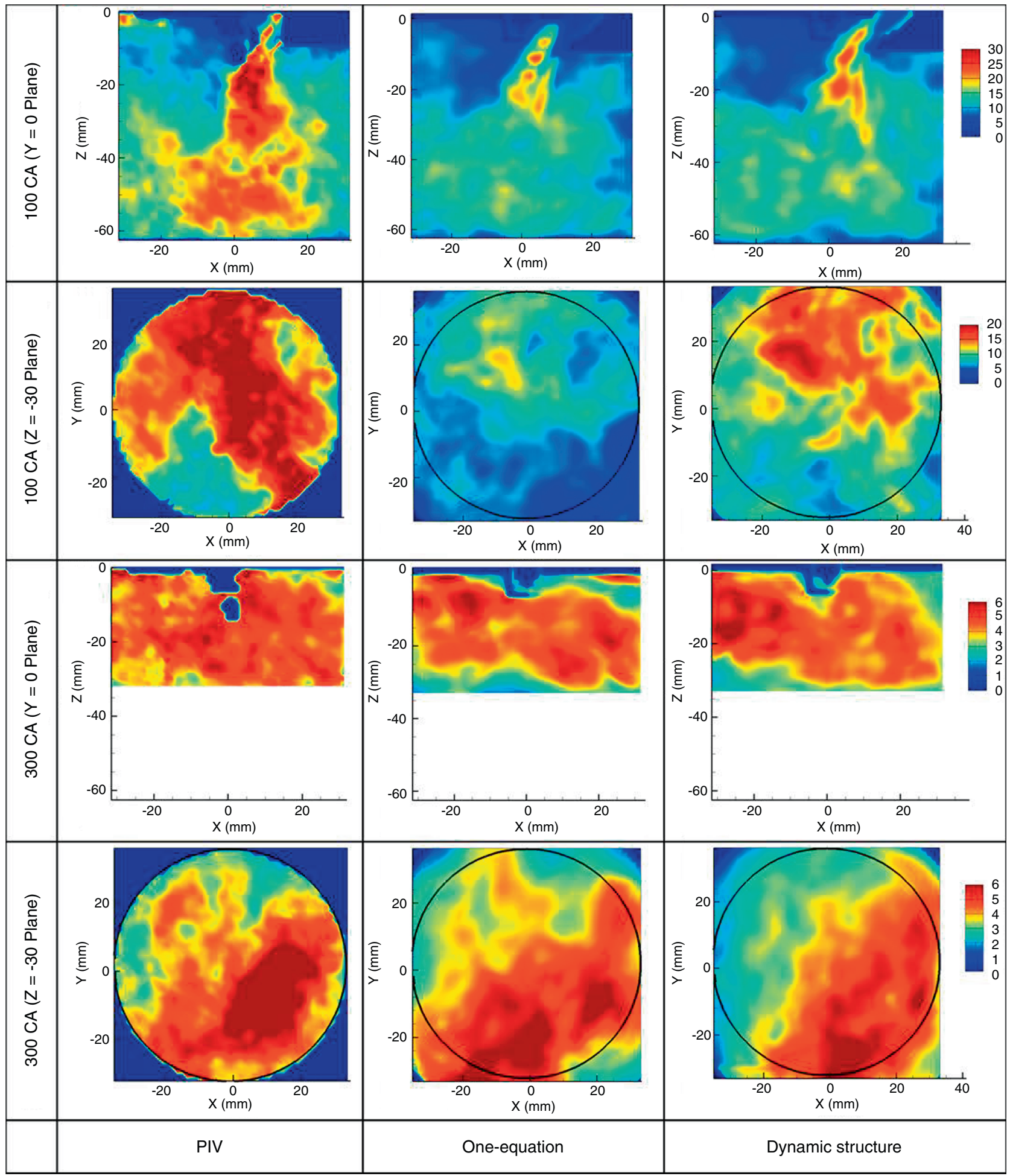

Figure 11

PIV and LES ensemble averaged RMS velocities (RMS velocity magnitude color-coded, in $\mathrm{m} / \mathrm{s}$ ) at various cutting planes and crank angle positions for $1300 \mathrm{rpm}, 95 \mathrm{kPa}$. Number of cycles used for RMS calculation is the same as in Figure 10. 


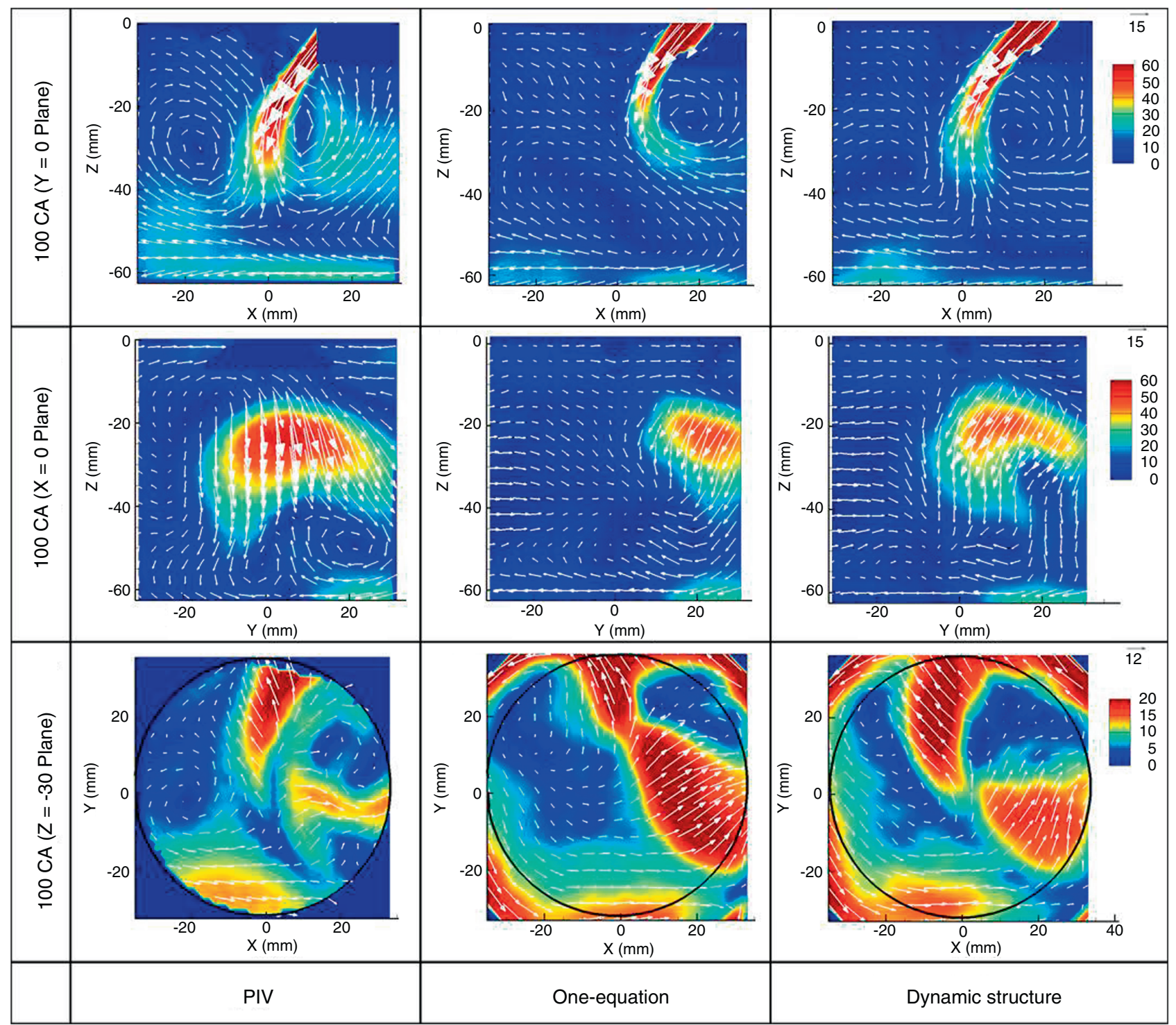

Figure 12

PIV and LES ensemble averaged mean flow velocities (velocity magnitude color-coded, in $\mathrm{m} / \mathrm{s}$ ) at 100 deg aTDCE and various cutting planes for $1300 \mathrm{rpm}, 40 \mathrm{kPa}$. Number of cycles used for ensemble average calculation: PIV $Y=0 \mathrm{~mm} \#=240$, PIV $X=0 \mathrm{~mm} \#=235$, PIV Z $=-30 \mathrm{~mm}$ $\#=1$ 157, one-equation \# = 20, dynamic structure \# $=20$.

\section{$1300 \mathrm{rpm}, 95 \mathrm{kPa}$}

Previous work [7] showed good agreement between LES one-equation model and PIV for $800 \mathrm{rpm}, 95 \mathrm{kPa}$. Thus, a first comparison will be shown for results from using the one-equation model with PIV for the current operating point.

The mean flow predicted by the one-equation model is shown in Figure 10. Intake jet penetration depth (100 CA, $Y=0$ plane) seems to be a little under-predicted. In the azimuthal (100 CA, $Z=-30$ ) cutting plane, the flow structures are captured well qualitatively, but the overall magnitude is smaller than in the experiments. During the compression stroke at $300 \mathrm{CA}$, for all cutting planes the mean velocity fields match reasonably well qualitatively, but the predicted magnitude is consistently lower than the experimental data.

Next the performance of the DSOE model was examined, which is expected to better resolve the sub-grid kinetic 


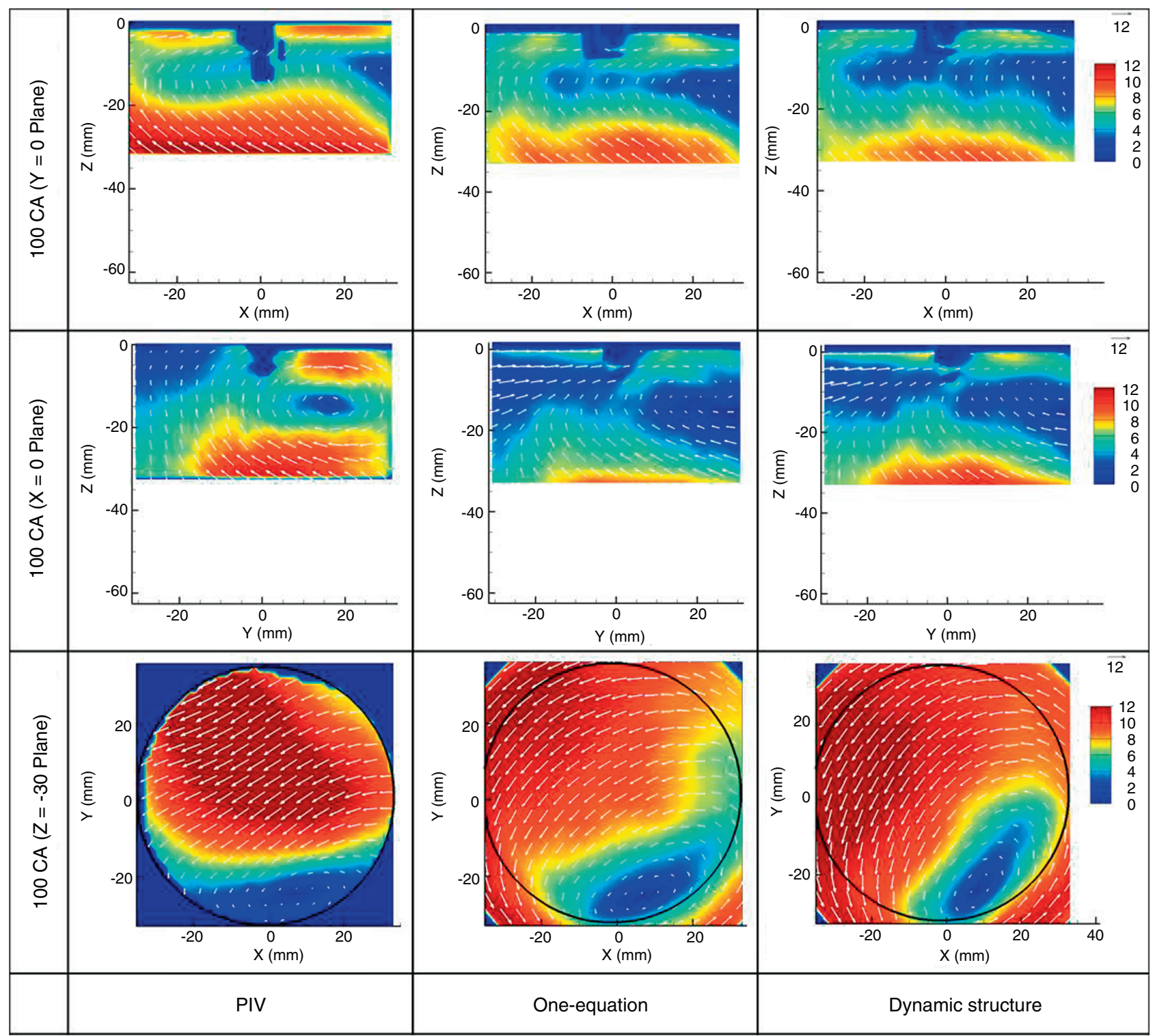

Figure 13

PIV and LES ensemble averaged mean flow velocities (velocity magnitude color-coded, in $\mathrm{m} / \mathrm{s}$ ) at 300 deg aTDCE and various cutting planes for $1300 \mathrm{rpm}, 40 \mathrm{kPa}$. Number of cycles used for ensemble average calculation is the same as in Figure 12.

energy because of a dynamic interaction with the resolved kinetic energy, rather than using the same model constant to compute the sub-grid kinetic energy as in the one-equation model. Figure 10 shows that there is not much improvement with the DSOE model over the one-equation model in terms of intake jet shape or penetration depth $(Y=0$ plane), but the agreement in the azimuthal $(Z=-30)$ plane becomes much better at $100 \mathrm{CA}$ for the former. Interestingly, the DSOE model under-predicts the compression flow $(Y=0$ plane at $300 \mathrm{CA})$ and the overall magnitude is even lower than for the one-equation model. There is not much difference in the two models for azimuthal $(Z=-30$ plane) mean flow at $300 \mathrm{CA}$ beyond a small difference in the swirl magnitude.

Figure 11 shows that RMS is consistently under-predicted especially during the intake stroke. However, some regions of large RMS (within and at the bottom of the intake jet at $100 \mathrm{CA}, Y=0$ plane; the bottom of the domain at $300 \mathrm{CA}, Y=0$ plane and $Z=-30$ plane) are correctly captured by both the models. At $100 \mathrm{CA}, Z=-30$ plane, 


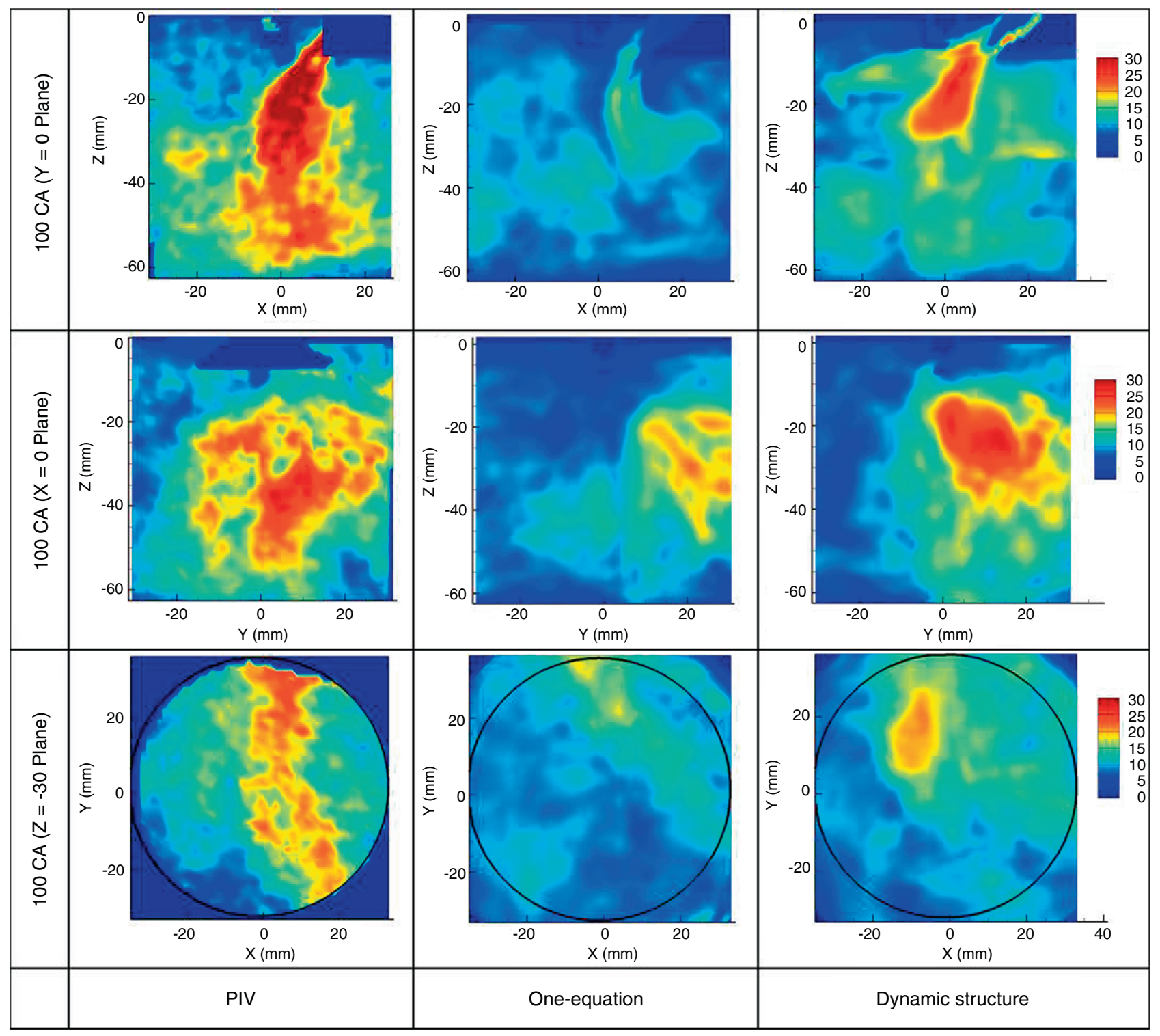

Figure 14

PIV and LES ensemble RMS flow velocities (RMS velocity magnitude color-coded, in m/s) at 100 deg aTDCE and various cutting planes for $1300 \mathrm{rpm}, 40 \mathrm{kPa}$. Number of cycles used for RMS calculation is the same as in Figure 12.

neither model captures the correct qualitative trends. Our previous study [7] shows that by adding the SGS turbulent fluctuation u' to LES-calculated RMS values, the agreement between PIV measurement and LES prediction can be further improved.

From the above discussion, it seems that both oneequation and DSOE models do a good job in capturing some of the features of the flow field, but no overarching conclusions as to which model performs better can be made for this operating point.

\section{$1300 \mathrm{rpm}, 40 \mathrm{kPa}$}

The overall goal of the GM-UM collaboration is to develop LES tools to predict cyclic variability of engine flows in the presence of combustion. For optical engine experiments with combustion, the intake manifold pressure has to be maintained at a much lower level than the ambient because the optical cylinder setup is rated only to $6 \mathrm{MPa}$ peak pressure. In this study therefore the motored flow at a MAP of $40 \mathrm{kPa}$ was examined, as a pre-cursor to capturing flows with combustion. 


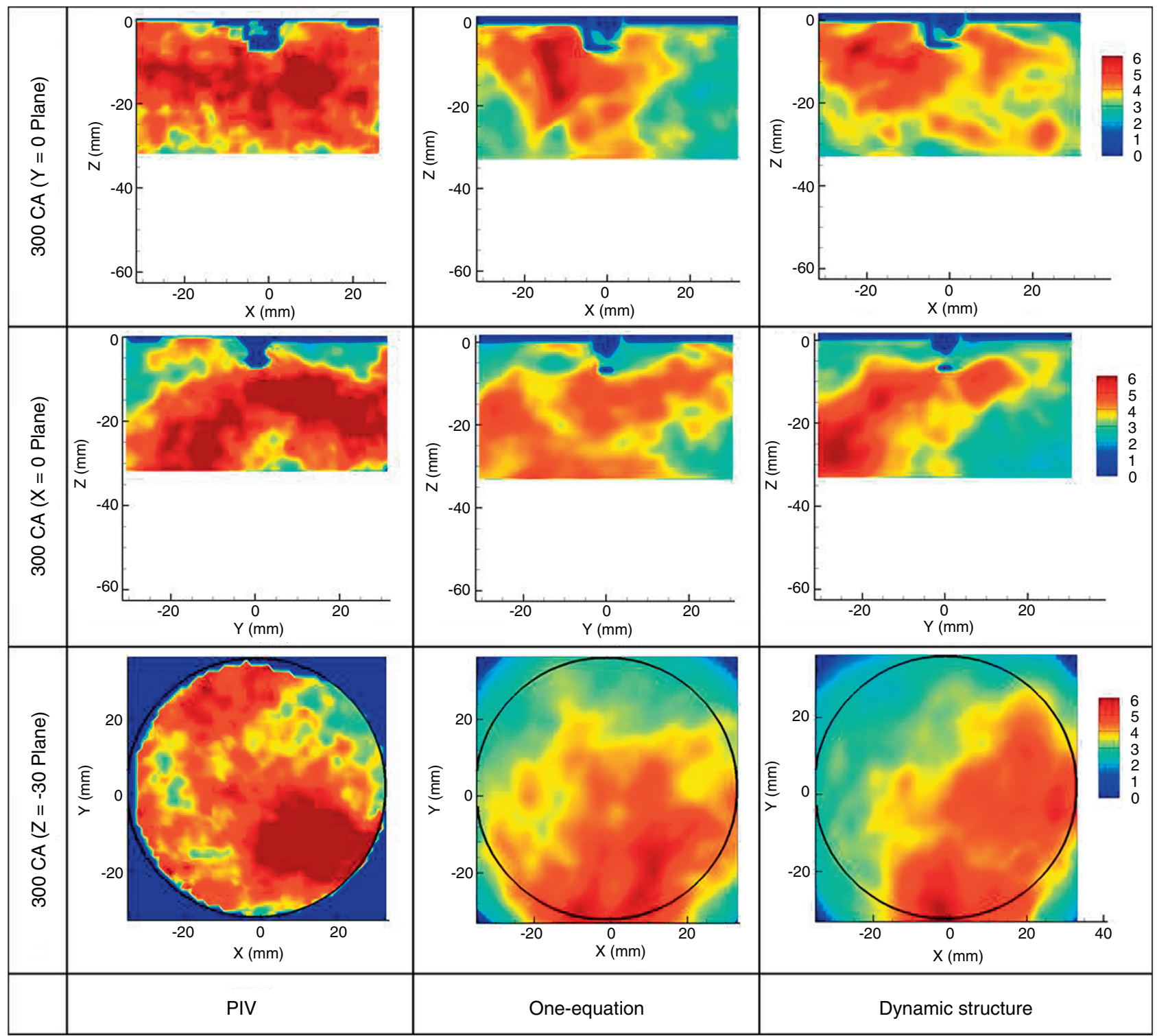

Figure 15

PIV and LES ensemble RMS flow velocities (RMS velocity magnitude color-coded, in $\mathrm{m} / \mathrm{s}$ ) at 300 deg aTDCE and various cutting planes for $1300 \mathrm{rpm}, 40 \mathrm{kPa}$. Number of cycles used for RMS calculation is the same as in Figure 12.

As in the previous section, both one-equation and DSOE models were studied with a compilation of results shown in Figures 12-15. The velocity fields shown are taken for the same CA positions as before (intake jet: $100 \mathrm{CA}$ and compression flow: $300 \mathrm{CA}$ ). Clearly, the use of the DSOE model results in a prediction that is far closer to the experimentally determined flow fields at $100 \mathrm{CA}$ than what is obtained with the one-equation model (Fig. 12). The shape of the intake jet along with its penetration depth and the surrounding vortical flow structures are captured more accurately in the $Y=0$ plane.

The $X=0$ cross section of the intake jet follows that trend as well. For the $Z=-30$ plane the magnitude and overall structural features of the flow are again better captured with the DSOE model. Figure 13 shows that at $300 \mathrm{CA}$, however, both the models predict similar trends for all cutting planes.

In general, RMS magnitudes are consistently under-predicted by both the models (Fig. 14, 15), with the DSOE model predicting more accurate RMS distributions than 


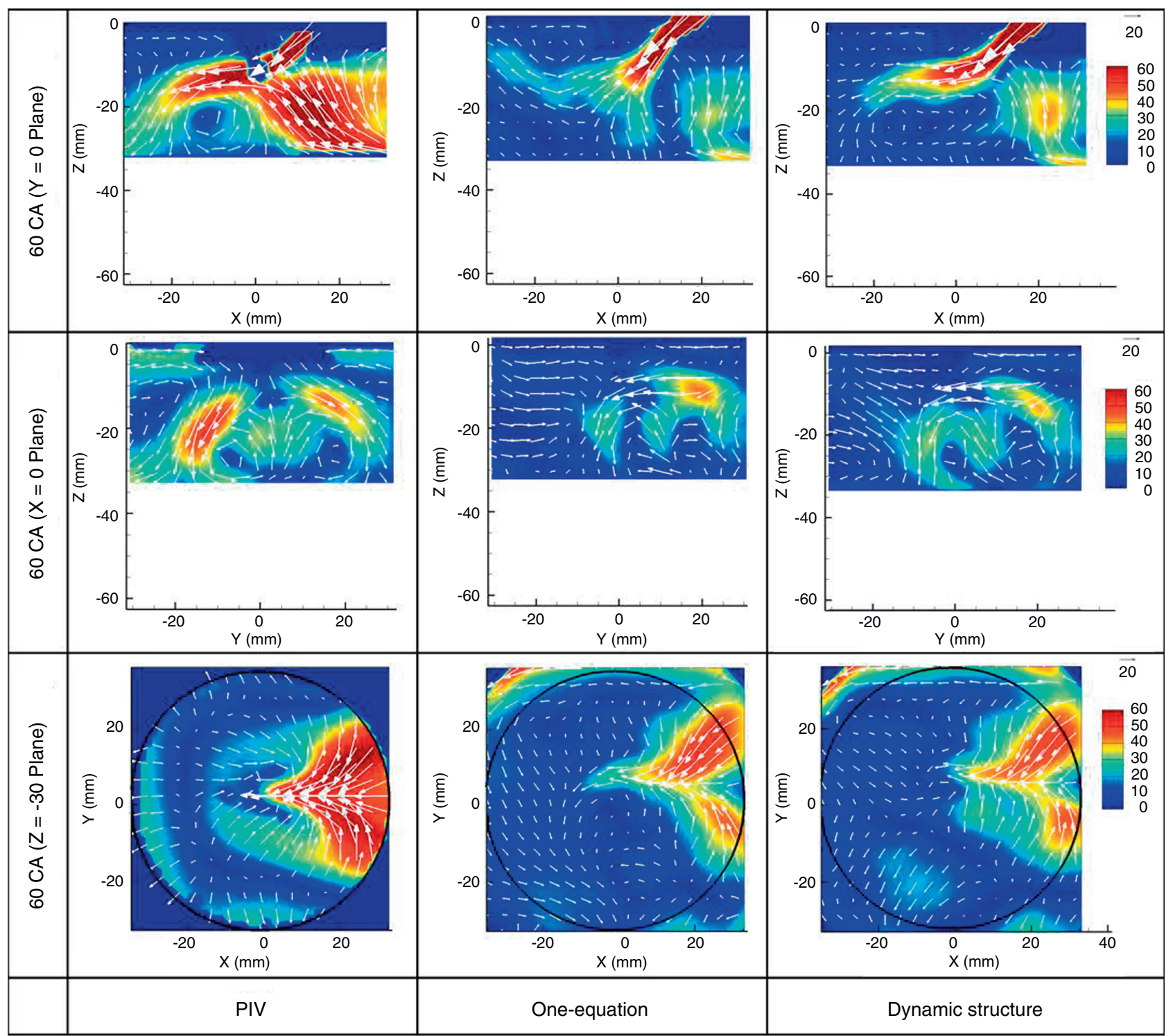

Figure 16

PIV and LES ensemble averaged mean flow velocities (velocity magnitude color-coded, in $\mathrm{m} / \mathrm{s}$ ) at 60 deg aTDCE and various cutting planes for $1300 \mathrm{rpm}, 40 \mathrm{kPa}$. Number of cycles used for RMS calculation is the same as in Figure 12.

one-equation model at $100 \mathrm{CA}$ for the $X$ and $Y=0$ planes. However, in the horizontal plane and at $300 \mathrm{CA}$ both the models predict inaccurate distributions.

To summarize, for the $1300 \mathrm{rpm}, 40 \mathrm{kPa}$ operating point, both models give similar results for compression flow (300 CA), but the DSOE model performs better than oneequation model in capturing intake flow (100 CA), both in terms of mean and RMS velocity distributions. This is an important finding, as it is contrary to what was observed for $95 \mathrm{kPa}$, where both models performed similarly for both intake and compression flows.
The reason for this unexpected behavior could be found in the differences of the bulk intake flow that was discussed in the context of Figure 9. What is the difference between the intake flow at $95 \mathrm{kPa}$ versus $40 \mathrm{kPa}$ ? As seen in Figure 9a, there is a larger backflow from cylinder to intake port for $40 \mathrm{kPa}$ because of a reverse pressure gradient. This makes the overall intake flow structure at $40 \mathrm{kPa}$ much more complicated (in-flow and out-flow through the intake valve) than at $95 \mathrm{kPa}$. This implies that for such complex flows, the oneequation model fails to provide accurate results, and one needs to resort to the DSOE model. 


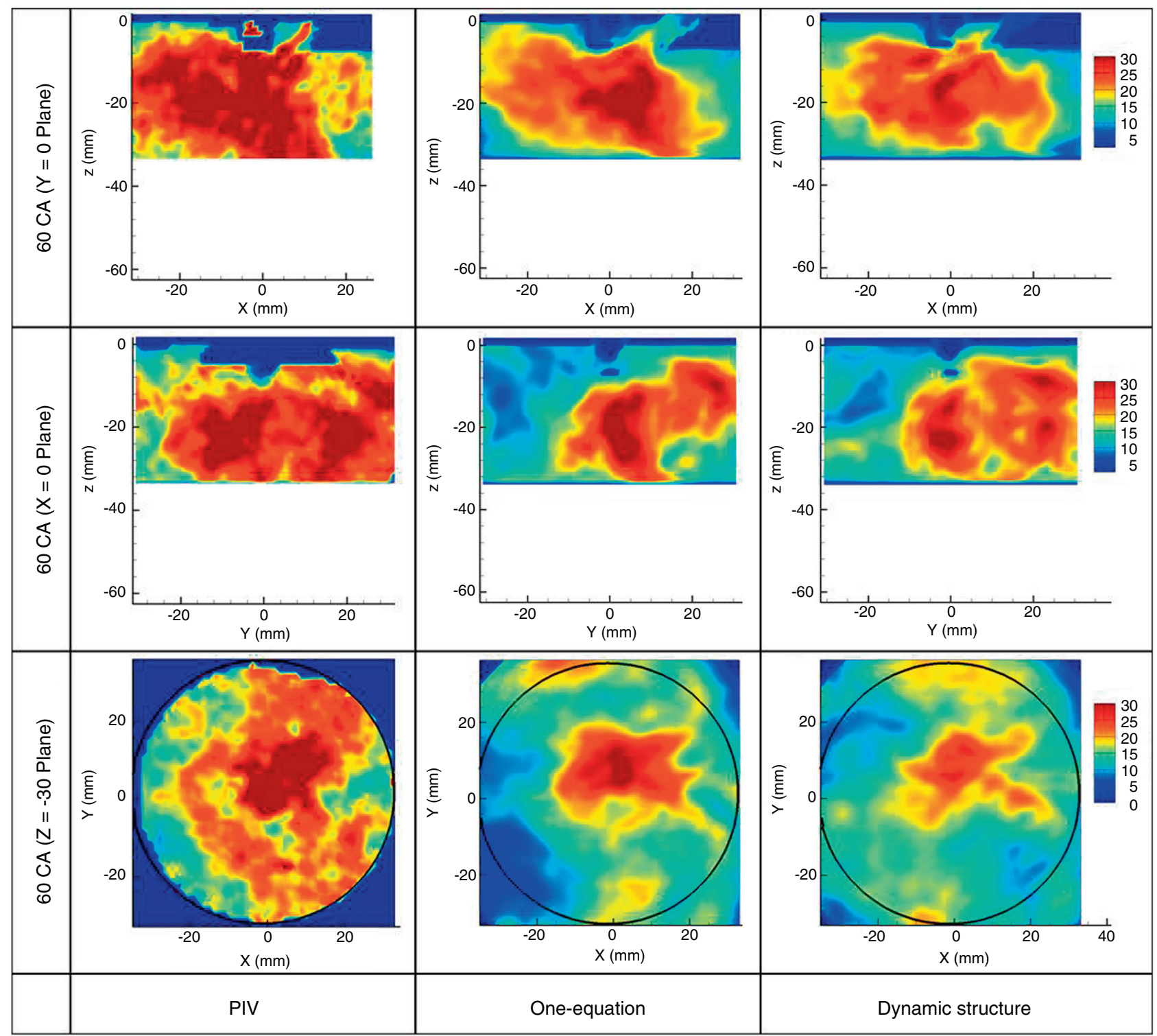

Figure 17

PIV and LES ensemble RMS flow velocities (RMS velocity magnitude color-coded, in $\mathrm{m} / \mathrm{s}$ ) at $60 \mathrm{deg}$ aTDCE and various cutting planes for $1300 \mathrm{rpm}, 40 \mathrm{kPa}$. Number of cycles used for RMS calculation is the same as in Figure 12.

In order to further substantiate the above point, the early intake flow was examined in greater detail. Figures 16 and 17 show the mean and RMS, respectively at 60 CA. Clearly, the DSOE model predicts the downward curved intake jet shape ( $Y=0$ plane) consistent with PIV, as opposed to a much weaker intake jet predicted by the one-equation model. Flow structures at $X=0$ plane and $Z=-30$ plane are similar between the two models, though. High RMS regions are adequately captured by both the models for all the cutting planes, although here too, the DSOE model performs marginally better.

\section{Mesh Refinement}

The observation that the early phase of the intake flow is so critical to the evolution of the flow indicated that the DSOE model could do better in capturing the high-gradient 


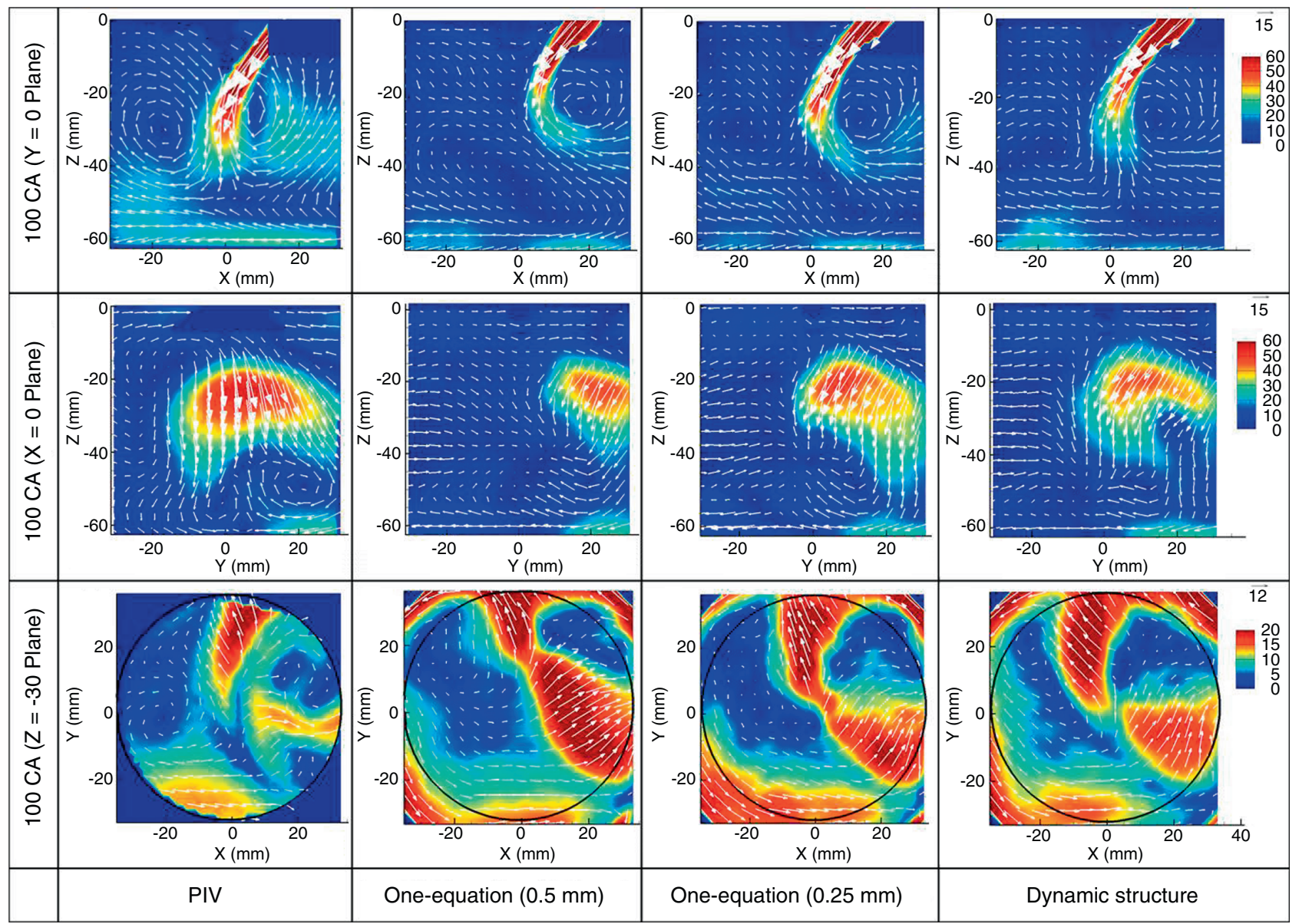

Figure 18

Mesh refinement study: PIV and LES ensemble-averaged mean flow velocities (velocity magnitude color-coded, in $\mathrm{m} / \mathrm{s}$ ) at $100 \mathrm{deg}$ aTDCE and various cutting planes for $1300 \mathrm{rpm}, 40 \mathrm{kPa}$. Number of cycles used for ensemble average calculation: PIV $Y=0 \mathrm{~mm} \#=240, P I V X=0 \mathrm{~mm}$ $\#=235$, PIV $Z=-30 \mathrm{~mm} \#=1157$, one-equation $(0.5 \mathrm{~mm}) \#=20$, one-equation $(0.25 \mathrm{~mm}) \#=20$, dynamic structure \# $=20$.

flow regions. Another critical aspect, though, is the way valve opening and closing events are handled in CFD. In the physical engine setup and the experiments the valve lift curves are continuous and smooth functions in time. In a CFD simulation, however, the valve opening event is an abrupt process that will switch the valve position from fully closed to open at a pre-set valve lift, typically a fraction of a millimeter, from one time step to the next. Thus, the initial inflow conditions will be substantially affected by this minimum valve lift setting, especially for conditions where there is a substantial initial pressure difference across the valve.

A potential means to better capture the complex flow at $40 \mathrm{kPa}$ then is to refine the mesh close to the valve seats, as finer meshes may allow resolving the detailed flow structures better. In an attempt to improve the earlier one-equation model results for intake flow at $40 \mathrm{kPa}$, the smallest mesh size close to the valve seat was reduced to $0.25 \mathrm{~mm}$ as opposed to the regular $0.5 \mathrm{~mm}$. This comes at a substantial computational expense and the simulations with finer mesh took three times longer to finish.

The mean flow results are presented in Figure 18 for 20 cycles and clearly show that mesh refinement leads to much better results; with more accurate intake jet penetration depth in the $Y=0$ plane, and better quantitative agreements at the bottom of the spark plug in the $X=0$ and the $Z=-30$ planes. For comparison, the results from the DSOE model but with coarser grid are also shown again here. This illustrates how mesh refinement and the increased ability of a DSOE model better capture gradients. Figure 19 makes the same point for the RMS velocity distributions. Thus, it is expected that future computations with a finer mesh around the valves and the DSOE model will further increase the accuracy of the simulations. 


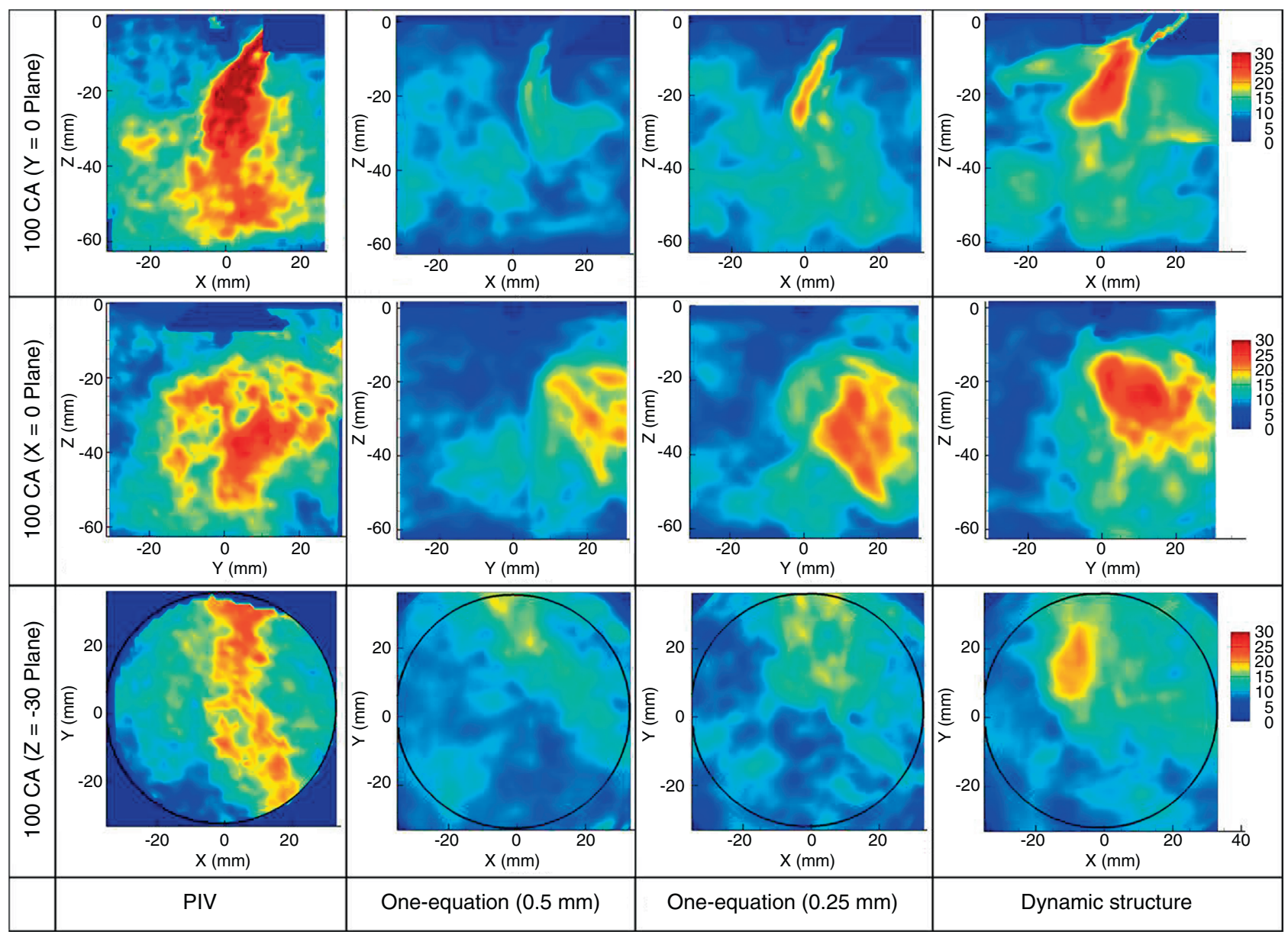

Figure 19

Mesh refinement study: PIV and LES ensemble RMS flow velocities (RMS velocity magnitude color-coded, in m/s) at 100 deg aTDCE and various cutting planes for $1300 \mathrm{rpm}, 40 \mathrm{kPa}$. Number of cycles used for RMS calculation is the same as in Figure 18 .

Further experimental results are obtained at $800 \mathrm{RPM}$ and $95 \mathrm{kPa}$ in the TCC-III configuration (not presented here, but are available for download from http://deepblue.lib.umich. edu/handle/2027.42/108382) with the purpose to inspire future investigations that explore the impact of SGS models and meshing details by using parametric variations.

\section{CONCLUSIONS}

A comprehensive study was conducted to characterize the flow field in an optical engine, the TCC-III engine, to advance the predictive capability of LES. Experiments, 1D simulations, and LES were performed for motored engine conditions as a baseline for a study of the origins of cyclic variability in engine performance. High-speed PIV was used to capture the flow in hundreds of consecutive cycles with 5 CA degree steps. Successive measurements in all three orthogonal directions were performed over the course of a six-month period. Repeatability from test to test and within individual runs was shown to be very high, exceeding the experimental uncertainty of the measurements. The experiments were carried out for $1300 \mathrm{rpm}$ and 40 and $95 \mathrm{kPa}$ intake manifold pressures as well as for $800 \mathrm{rpm}$ and $95 \mathrm{kPa}$ MAP to enable a thorough assessment of the performance of two subgrid scale models used in LES that were performed with CONVERGE. A one-equation eddy viscosity model and a DSOE model were used with CONVERGE to perform computations for 20 consecutive engine cycles for each operating condition.

The experimental data was used to guide the selection of SGS models and assess their strength and weaknesses. In that context, the investigation of multiple operating conditions was critical for the analysis.

The simulation results from both SGS models show a trend that under predicts the magnitude of the mean flow 
and of the RMS velocity fields. However, it is noted that the spatial structure of the RMS velocity field in some observation planes is better captured in LES using the DSOE model. The differences were highest during the intake stroke and less pronounced during the compression stroke. This is plausible because the performance of the DSOE model is expected to be better in regions with high velocity gradients, such as during the intake when fast flowing air enters the cylinder. Contrasting the flows observed in low MAP operation $(40 \mathrm{kPa})$ with those seen at $95 \mathrm{kPa}$ reveals substantial differences in the dynamics of the bulk flow.

An investigation of early stage flow structures after intake valve opening pointed to the limited resolution of the computational mesh and the stepwise opening of the valve, a necessary procedure in CFD. Refinement of the computational mesh from $0.5 \mathrm{~mm}$ to $0.25 \mathrm{~mm}$ around the valve improved the simulation accuracy even for the one-equation model quite substantially. Future computations will include refined meshing around the valve in combination with the DSOE model and also a parametric study of the flow at different engine speeds.

The data, along with the geometry of the engine and a complete GT Power model are available for benchmarking and model development from:

http://deepblue.lib.umich.edu/handle/2027.42/108382

\section{ACKNOWLEDGMENTS}

Funding for this work was provided by the General Motors/ University of Michigan Automotive Collaborative Research Laboratory, Engine Systems Division. We also acknowledge Kevin Peterson (GM Global R\&D), Richard Davis (GM Powertrain), and Norm Maasshoff (GM Powertrain) for their valuable technical experience and support. Finally, Convergent Sciences is acknowledged for providing licenses to the University of Michigan to run additional simulations to assess the meshing dimensions around the valves.

\section{REFERENCES}

1 Merker G.P., Schwarz C. (2009) Grundlagen Verbrennungsmotoren, Springer.

2 Haworth D.C. (1999) Large-eddy simulation of in-cylinder flows, Oil \& Gas Science and Technology 54, 2, 175-185.

3 Thobois L., Lauvergne R., Poinsot T. (2007) Using LES to investigate reacting flow physics in engine design process, SAE Paper 2007-01-0166.

4 Granet V., Vermorel O., Lacour C., Enaux B., Dugué V., Poinsot T. (2012) Large-Eddy Simulation and experimental study of cycle-to-cycle variations of stable and unstable operating points in a spark ignition engine, Combustion and Flame 159, 1562-1575.
5 Pera C., Angelberger C. (2011) Large Eddy Simulation of a Motored Single-Cylinder Engine Using System Simulation to Define Boundary Conditions: Methodology and Validation, SAE Int. J. Engines 4, 1, 948-963. DOI: 10.4271/2011-01-0834.

6 Goryntsev D., Sadiki A., Klein M., Janicka J. (2009) Large eddy simulation based analysis of the effects of cycle-to-cycle variations on air-fuel mixing in realistic DISI IC-engines, Proc. Comb. Inst. 32, 2, 2759-2766.

7 Kuo T.-W., Yang X., Gopalakrishnan V., Chen Z. (2014) Large Eddy Simulation (LES) for IC Engine Flows, Oil \& Gas Science and Technology 69, 1, 61-81.

8 Rutland C.J. (2011) Large-eddy simulations for internal combustion engines - a review, International Journal of Engine Research 12, 4, 421-451.

9 Yang X., Gupta S., Kuo T.-W., Gopalakrishnan V. (2013) RANS and LES of IC Engine Flows: A Comparative Study, ASME 2013 Internal Combustion Engine Division Fall Technical Conference, American Society of Mechanical Engineers.

10 Morse A.P., Whitelaw J.H., Yianneskis M. (1979) Turbulent Flow Measurements by Laser-Doppler Anemometry in a Motored Piston-Cylinder Assemblies, Journal of Fluids Engineering 101, 2, 208-216.

11 Lacour C., Pera C. (2011) An experimental Database Dedicated to the Study and Modelling of Cyclic Variability in Spark-Ignition Engines with LES, SAE Technical Paper 2011-01-1282.

12 Baum E., Peterson B., Böhm B., Dreizler A. (2014) On the validation of LES applied to internal combustion engine flows: Part 1: comprehensive experimental database, Flow, Turbulence and Combustion 92, 1-2, 269-297.

13 Sick V., Reuss D., Abraham P., Alhardi A., Almagri O., Chen H., Rutland C., Zhang Y., Haworth D., Liu K., Oefelein J., Janicka J., Goryntsev D., Kuo T.-W., Yang X., Gopalakrishnan V. (2010) A Common Engine Platform for Engine LES Development and Validation, LES4ICE 2010, IFP Energies Nouvelles, Rueil-Malmaison, France.

14 Reuss D.L. (2000) Cyclic Variability of Large-Scale Turbulent Structures in Directed and Undirected IC Engine Flows, $S A E$ Technical Paper 2000-01-0246.

15 Kuo T.-W., Reuss D.L. (1995) Multidimensional Port and Cylinder Flow Calculations for the Transparent-CombustionChamber Engine, Engine Modeling, ICE-Vol. 23, Uzkan T., ASME, pp. 19-30

16 Reuss D.L., Bardsley M., Felton P.G., Landreth C.C., Adrian R.J. (1990) Velocity, Vorticity, and Strain-Rate Ahead of a Flame Measured in an Engine Using Particle Image Velocimetry, $S A E$ Technical Paper 900053.

17 Reuss D.L., Adrian R.J., Landreth C.C., French D.T., Fansler T.D. (1989) Instantaneous Planar Measurements of Velocity and Large-Scale Vorticity and Strain Rate in an Engine Using Particle-Image Velocimetry, SAE Technical Paper 890616.

18 Abraham P., Liu K., Haworth D., Reuss D., Sick V. (2014) Evaluating Large-Eddy Simulation (LES) and High-Speed Particle Image Velocimetry (PIV) with Phase-Invariant Proper Orthogonal Decomposition (POD), Oil \& Gas Science and Technology 69, 1, 41-59.

19 Abraham P.S., Yang X., Gupta S., Kuo T.-W., Reuss D.L., Sick V. (2015) Flow-pattern switching in a motored spark ignition engine, International Journal of Engine Research 16, 3, 323-339.

20 Abraham P., Reuss D., Sick V. (2013) High-speed particle image velocimetry study of in-cylinder flows with improved dynamic range, SAE Technical Paper 2013-01-0542. 
21 Adrian R. (1997) Dynamic ranges of velocity and spatial resolution of particle image velocimetry, Measurement Science and Technology 8, 1393-1398.

22 Reuss D.L., Megerle M., Sick V. (2002) Particle-image velocimetry Measurement Errors when Imaging through a Transparent Engine Cylinder, Measurement Science and Technology 13, 1029-1035.

23 Megerle M., Sick V., Reuss D.L. (2002) Measurement of Digital PIV Precision using Electrooptically-Created ParticleImage Displacements, Measurement Science and Technology 13, 997-1005.

24 Baker R., Hutchinson P., Whitelaw J. (1974) Velocity measurements in the recirculation region of an industrial burner flame by laser anemometry with light frequency shifting, Combustion and Flame 23, 1, 57-71.

25 CONVERGE $^{\mathrm{TM}}$ (2009) CONVERGE ${ }^{T M}$ : A Three-Dimensional Computational Fluid Dynamics Program for Transient Flows with Complex Geometries, Convergent Science Inc.

26 Pomraning E. (2000) Development of large eddy simulation turbulence models, University of Wisconsin Madison.

27 Werner H., Wengle H. (1991) Large-eddy simulation of turbulent flow over and around a cube in a plate channel, Eighth Symposium on Turbulent Shear Flows, Munich, Germany, 9-11 Sept., Session 19-4.
28 Yoshizawa A., Horiuti K. (1985) A statistically-Derived Subgrid-Scale Kinetic Energy Model for the Large-Eddy Simulation of Turbulent Flows, Journal of the Physical Society of Japan 54, 8, 2834-2839.

29 Menon S., Yeung P.-K., Kim W.-W. (1996) Effect of Subgrid Models on the Computed Interscale Energy Transfer in Isotropic Turbulence, Computers and Fluids 25, 2, 165-180.

30 Pomraning E., Rutland C.J. (2002) A Dynamic One-Equation Non-Viscosity LES Model, AIAA Journal 40, 4, 689-701.

31 Ghosal S., Lund T.S., Moin P., Akselvoll K. (1995) A dynamic localization model for large-eddy simulation of turbulent flows, J. Fluid Mech. 286, 229-255.

32 Germano M., Piomelli U., Moin P., Cabot W.H. (1991) A dynamic subgrid-scale eddy viscosity model, Physics of Fluids A: Fluid Dynamics (1989-1993) 3, 7, 1760-1765.

33 Werner H., Wengle H. (1993) Large-Eddy Simulation of Turbulent Flow Over and Around a Cube in a Plate Channel, Turbulent Shear Flows 8, 155-168.

Manuscript submitted in September 2015

Manuscript accepted in July 2015

Published online in October 2015

Cite this article as: P. Schiffmann, S. Gupta, D. Reuss, V. Sick, X. Yang and T.-W. Kuo (2015). TCC-III Engine Benchmark for Large-Eddy Simulation of IC Engine Flows, Oil Gas Sci. Technol 71, 3. 


\section{APPENDIX A}

\section{TCC-III Engine and Data Specifications}

TABLE A1

Engine geometry

\begin{tabular}{c|c|c|c}
\hline Bore (cm) & 9.20 & Conrod length (cm) & 23.10 \\
\hline Stroke (cm) & 8.60 & piston-pin offset (cm) & 0.00 \\
\hline Clearance @ TDC & 0.95 & EVC, aTDCexh & 12.80 \\
\hline Comb chamber (cc) & 63.15 & IPL, aTDCexh & 240.8 \\
\hline Top land crevice (cc) & 0.37 & IVC, aTDCexh & 484.8 \\
\hline Spkplug crevice (cc) & 0.02 & EVO, aTDCexh & 606.8 \\
\hline TDC vol. (cc) & 63.54 & EPL, aTDCexh & 712.8 \\
\hline Swept vol. (cc) & 571.7 & IVO, aTDCexh & R44LTS \\
\hline Geometric CR & 10.00 & Delco Spk Plg & $30 / 45 / 60 / 75$ \\
\hline Effective (IVC) CR & 8.00 & Steady-flow swirl ratio & 0.4 \\
\hline
\end{tabular}

TABLE A2

Data precision

\begin{tabular}{c|c|c|c|c}
\hline Set point parameter name & Set point & $\begin{array}{c}\text { Max deviations from set } \\
\text { point of test avg }\end{array}$ & Average in test stdev & GT power model \\
\hline Engine speed (RPM) & $800 / 1300 / 1300$ & $0.9 / 1.1 / 0.8$ & $0.6 / 0.4 / 0.6$ & $800 / 1300 / 1300$ \\
\hline $\begin{array}{c}\text { Pressure at intake plenum } \\
\text { inlet (kPaa) }\end{array}$ & $95 / 95 / 40$ & $0.3 / 0.13 / 0.3$ & $0.05 / 0.09 / 0.05$ & $95.2 / 95.1 / 40.0$ \\
\hline $\begin{array}{c}\text { Pressure at exhaust plenum } \\
\text { outlet (kPaa) }\end{array}$ & $101.5 / 101.5 / 101.5$ & $0.2 / 0.12 / 0.2$ & $0.03 / 0.02 / 0.03$ & $401.2 / 101.1 / 101.5$ \\
\hline $\begin{array}{c}\text { Air temperature intake port } \\
\left({ }^{\circ} \mathrm{C}\right)\end{array}$ & $45 / 45 / 45$ & $0.9 / 1.0 /-1.2$ & $0 / 0 / 0$ & $45 / 45 / 45$ \\
\hline $\begin{array}{c}\text { Engine oil temperature at } \\
\text { inlet }\left({ }^{\circ} \mathrm{C}\right)\end{array}$ & $45 / 45 / 45$ & $-14 /-4 /-6$ & $0 / 0 / 0$ & $45 / 45 / 45$ \\
\hline $\begin{array}{c}\text { Engine coolant temperature } \\
\text { at outlet }\left({ }^{\circ} \mathrm{C}\right)\end{array}$ & $45 / 45 / 45$ & $0.1 / 0.3 /-2.5$ & $0 / 0 / 0$ & $45 / 45 / 45$ \\
\hline
\end{tabular}


TABLE A2 (continued)

\begin{tabular}{c|c|c|c|c}
\hline Measured parameter name & Average of all tests & $\begin{array}{c}\text { Max deviation from all test } \\
\text { avg to single test avg }\end{array}$ & Average in test stdev & GT power model \\
\hline $\begin{array}{c}\text { Pressure at intake port } \\
(\mathrm{kPaa})\end{array}$ & $94.6 / 94.4 / 39.5$ & $0.4 / 0.1 / 0.3$ & $0.05 / 0.1 / 0.05$ & $95.1 / 94.8 / 39.8$ \\
\hline $\begin{array}{c}\text { Pressure at exhaust port } \\
(\mathrm{kPaa})\end{array}$ & $101.7 / 101.8 / 101.1$ & $0.1 / 0.1 / 0.1$ & $0.03 / 0.01 / 0.03$ & $101.2 / 101.1 / 100.9$ \\
\hline $\begin{array}{c}\text { Indicated mean effective } \\
\text { pressure }(\mathrm{kPa})\end{array}$ & $-41.9 /-37.8 /-19.6$ & $0.9 / 0.1 / 1.0$ & $0.7 / 0.5 / 0.3$ & $1937 / 2013 / 836$ \\
\hline $\begin{array}{c}\text { Cylinder peak pressure } \\
(\mathrm{kPaa})\end{array}$ & $1810 / 1958 / 798$ & $16 / 0.6 / 7$ & $3.4 / 3.5 / 1.8$ & $359.5 / 359.5 / 359.5$ \\
\hline $\begin{array}{c}\text { Cylinder peak pressure } \\
\text { location (CA aTDCE) }\end{array}$ & $358.6 / 358.8 / 358.5$ & $0.01 / 0.03 / 0.07$ & $0.2 / 0.25 / 0.3$ & $45 / 45 / 45$ \\
\hline $\begin{array}{c}\text { Temperature at outside } \\
\text { cylinder wall }\left({ }^{\circ} \mathrm{C}\right)\end{array}$ & $36.9 / 40.8 / 41.0$ & $0.5 / 2.6 / 0.3$ & $0 / 0 / 0$ & $3.51 / 5.80 / 2.12$ \\
\hline Mass flow (g/s) & $3.5 / 5.88 / 2.07$ & $0.02 / 0.03 / 0.03$ & $0 / 0 / 0$ & \\
\hline
\end{tabular}

LES model results

\begin{tabular}{|c|c|c|c|c|c|}
\hline \multirow[b]{2}{*}{ Computed parameter } & \multicolumn{5}{|c|}{ LES model setup } \\
\hline & $80095 \mathrm{OE}$ & $130095 \mathrm{OE}$ & $130040 \mathrm{OE}$ & $\begin{array}{l}130040 \mathrm{OE} \\
\text { refined mesh }\end{array}$ & $130040 \mathrm{DS}$ \\
\hline $\begin{array}{l}\text { Pressure at intake port } \\
\qquad(\mathrm{kPaa})\end{array}$ & 94.8 & 94.5 & 39.7 & 39.8 & 39.6 \\
\hline $\begin{array}{c}\text { Pressure at exhaust } \\
\text { port (kPaa) }\end{array}$ & 101.4 & 101.3 & 100.8 & 100.8 & 100.8 \\
\hline $\begin{array}{l}\text { Cylinder peak } \\
\text { pressure }(\mathrm{kPaa})\end{array}$ & 1863 & 1941 & 807 & 810 & 813 \\
\hline $\begin{array}{l}\text { Cylinder peak } \\
\text { pressure location } \\
\text { (CA aTDCE) }\end{array}$ & 359.5 & 359.5 & 359.5 & 359.3 & 359.5 \\
\hline Mass flow (g/s) & 3.50 & 5.85 & 2.13 & 2.12 & 2.13 \\
\hline
\end{tabular}

Note: Motored parameter values in the table are organized according to engine speed and MAP operating condition, i.e., parameter value at ( $800 \mathrm{rpm}, 95 \mathrm{kPa} /$ (1 $300 \mathrm{rpm}, 95 \mathrm{kPa}) /(1300 \mathrm{rpm}, 40 \mathrm{kPa}$ ). 
TABLE A3

Data Set Labels

\begin{tabular}{|c|c|c|c|c|}
\hline PIV plane & $\mathrm{Y}=0 \mathrm{~mm}$ & $\mathrm{X}=0 \mathrm{~mm}$ & $\mathrm{z}=-5 \mathrm{~mm}$ & $\mathrm{z}=-30 \mathrm{~mm}$ \\
\hline 800 RPM $95 \mathrm{kPa}$ & $\begin{array}{c}\text { S_2014_05_20_02 } \\
0-705 \text { CAD } \\
\text { 40-705CAD } \\
235 \text { cyc }\end{array}$ & No data & $\begin{array}{c}\text { S_2014_05_13_03 } \\
0-705 \mathrm{CAD} \\
0-705 \mathrm{CAD} \\
286 \mathrm{cyc}\end{array}$ & $\begin{array}{c}\text { S_2 014_04_17_02 } \\
55-300 \text { CAD } \\
\text { 60-300CAD } \\
1157 \text { cyc }\end{array}$ \\
\hline $1300 \mathrm{RPM} 95 \mathrm{kPa}$ & $\begin{array}{c}\text { S_2014_05_20_01 } \\
0-705 \mathrm{CAD} \\
\text { 40-705CAD } \\
235 \text { cyc }\end{array}$ & No data & $\begin{array}{c}\text { S_2014_05_13_02 } \\
0-705 \mathrm{CAD} \\
0-705 \mathrm{CAD} \\
407 \mathrm{cyc}\end{array}$ & $\begin{array}{c}\text { S_2014_04_17_0 } \\
155-300 \mathrm{CAD} \\
60-300 \mathrm{CAD} \\
1157 \mathrm{cyc}\end{array}$ \\
\hline \multirow{4}{*}{$1300 \mathrm{RPM} 40 \mathrm{kPa}$} & $\begin{array}{c}\text { S_2013_10_24_01 } \\
0-690 \mathrm{CAD} \\
0-690 \mathrm{CAD} \\
240 \text { cyc }\end{array}$ & $\begin{array}{c}\text { S_2014_01_30_01 } \\
0-705 \mathrm{CAD} \\
0-705 \mathrm{CAD} \\
235 \mathrm{cyc}\end{array}$ & $\begin{array}{c}\text { S_2014_05_05_01 } \\
0-705 \mathrm{CAD} \\
0-705 \mathrm{CAD} \\
407 \mathrm{cyc}\end{array}$ & $\begin{array}{c}\text { S_2014_03_26_01 } \\
55-300 \mathrm{CAD} \\
\text { 60-300CAD } \\
1134 \text { cyc }\end{array}$ \\
\hline & $\begin{array}{c}\text { S_2013_11_07_02 } \\
0-690 \mathrm{CAD} \\
0-690 \mathrm{CAD} \\
240 \text { cyc }\end{array}$ & $\begin{array}{c}\text { S_2014_02_04_01 } \\
0-705 \mathrm{CAD} \\
0-705 \mathrm{CAD} \\
235 \mathrm{cyc}\end{array}$ & $\begin{array}{c}\text { S_2014_05_05_02 } \\
0-705 \mathrm{CAD} \\
0-705 \mathrm{CAD} \\
407 \mathrm{cyc}\end{array}$ & $\begin{array}{c}\text { S_2014_04_03_01 } \\
\text { 55-300CAD } \\
\text { 60-300CAD } \\
1134 \text { cyc }\end{array}$ \\
\hline & $\begin{array}{c}\text { S_2013_11_11_01 } \\
0-712.5 \mathrm{CAD} \\
0-712.5 \mathrm{CAD} \\
116 \text { cyc }\end{array}$ & $\begin{array}{c}\text { S_2014_02_05_02 } \\
0-705 \mathrm{CAD} \\
0-705 \mathrm{CAD} \\
235 \mathrm{cyc}\end{array}$ & $\begin{array}{c}\text { S_2014_05_07_01 } \\
0-705 \mathrm{CAD} \\
0-705 \mathrm{CAD} \\
407 \text { cyc }\end{array}$ & $\begin{array}{c}\text { S_2014_04_16_02 } \\
55-300 \mathrm{CAD} \\
60-300 \mathrm{CAD} \\
1157 \text { cyc }\end{array}$ \\
\hline & $\begin{array}{c}\text { S_2014_05_20_03 } \\
40-300 \mathrm{CAD} \\
50,60,70,80,90,100, \\
180,220,260, \\
300 \mathrm{CAD} \\
3035 \mathrm{cyc}\end{array}$ & \multicolumn{2}{|c|}{$\begin{array}{c}\text { TEST ID } \\
\text { Recorded CA } \\
\text { posted CA } \\
\text { \# cycles }\end{array}$} & $\begin{array}{c}\text { S_2014_04_16_03_A } \\
55-300 \mathrm{CAD} \\
60-300 \mathrm{CAD} \\
400 \mathrm{cyc}\end{array}$ \\
\hline
\end{tabular}

